\title{
Herding in Chinese stock markets: a nonparametric approach
}

\author{
Syed F. Mahmud ${ }^{1}$ • Murat Tiniç ${ }^{2}$
}

Received: 13 November 2015 / Accepted: 10 April 2017 / Published online: 4 July 2017

(C) Springer-Verlag GmbH Germany 2017

\begin{abstract}
The paper reports new evidence of herding in the Chinese A-type and Btype markets by employing nonparametric kernel regression. We find statistically significant evidence of herding in A-type market under both extreme high and low market returns. Herding in B-type market, which predominantly consists of foreign investors, indicates only weak evidence of herding. We do not find any statistically significant evidence of herding in the pre-2001 sample of B-type market, when only foreign investors could do the trading. Lack of knowledge and experience of local investors may be attributed to the presence of herd behaviour in the Chinese markets.
\end{abstract}

Keywords Herding behaviour - Chinese stock market · Nonparametric regression

JEL Classification $\mathrm{G} 15 \cdot \mathrm{G} 14$

\section{Introduction}

Theoretical and empirical research in explaining herd behaviour of market participants has been diverse, and several approaches/models have been proposed in the literature. ${ }^{1}$ Research has also been focused in understanding how this behaviour may lead to inefficiencies in the market(s) by pushing the stock prices from their fundamental levels. Herd behaviour, in general, refers to the specific behaviour of investors in mimicking

\footnotetext{
1 For example Bikhchandani et al. (1992), Scharfstein and Stein (1990) and Devenow and Welch (1996) had developed theoretical models of herd behaviour.

$\triangle$ Syed F. Mahmud syed@bilkent.edu.tr

1 Department of Economics, Bilkent University, 06800 Ankara, Turkey

2 Department of Management, Bilkent University, 06800 Ankara, Turkey
} 
the actions of others. It has been argued that herd behaviour can be interpreted as rational, explained by the principal-agent problem, when fund managers may ignore their own assessment(s) and mimic the behaviour of others to maintain their reputation Scharfstein and Stein (1990). Numerous empirical studies have focused on detecting herd behaviour among mutual fund managers (for example, Wermers (1999), Gleason and Lee (2003) and Clement and Tse (2005) among others). However, the irrational view deals with the psychology of investors when they disregard their own beliefs and simply follow others and this can be detrimental to the efficiency of the market. In detecting the irrational herd behaviour, a sizeable body of literature employs the framework of the pioneering work of Christie and Huang (1995), where herding is detected by measuring the dispersion of stock returns with respect to market returns (hereafter referred as $\mathrm{CH}$ ). $\mathrm{CH}$ have argued that individual investors are likely to suppress their own convictions in favour of market consensus during unusual market conditions and low dispersions can be attributed to the herd behaviour. But all low dispersions do not indicate herd behaviour. For example, lack of information may yield low dispersions during a trading interval. However, during periods of extreme market conditions, low dispersions can be attributed to herd behaviour because under the rational asset pricing models these dispersions should increase because individual securities differ in their sensitivity to market return. Chang et al. (2000) extended the work in which cross-sectional absolute dispersion of stock returns (CSAD) has been analysed to find evidence of herding in the market (hereafter referred as CCK). However, the conventional empirical framework of both $\mathrm{CH}$ and $\mathrm{CCK}$ relies on particular parametric specifications of these models. For example, in $\mathrm{CH}$ model, inclusion of dummy variables in linear parametric model to establish extreme conditions in the market is subjective in nature. Similarly, in CCK model, a quadratic parametric regression model has been employed to test for herd behaviour. Several alternative approaches have been employed in the empirical literature to circumvent the issue. For example, Celik (2013) has employed quantile regression model, using $1 \%$ and $5 \%$ criterion. Similarly, Chiang et al. (2013) have employed rolling regression technique to improve the methodology. These models have partially addressed some of the limitations of the traditional parametric approach.

In this paper, a nonparametric methodology has been employed, by estimating kernel regression model. The novelty of the approach is that it imposes no a priori restrictions on the underlying model and does not impose any subjective criterion to divide the sample into to analyse the herd behaviour. Kernel regression model has been employed to report new evidence on herd behaviour in the Chinese capital markets. There are very few stock markets in the world that restrict foreign investors to trade in certain types of stocks. The Shanghai Stock Exchange (SHSE) and Shenzhen Stock Exchange (SZSE) have been established in year 1990, and two types of shares had been introduced in these markets. A-type stocks can be traded in the local currency, Renminbi (RMB), and only by the Chinese investors. B-type stocks were initially sold to foreign investors only. However, after February 2001, both foreign and local investors could trade these stocks A and B types of stocks can be traded in both the markets, but as Tan et al. (2008) suggested, the characteristics of the investors are different across these stocks. A-type stocks dominated by the local investors, who lack in their knowledge 
and experience about investments. The differences in the characteristics of investors may lead to different herd behaviour in these markets.

There are number of studies that have examined herd behaviour in the Chinese markets. The overall outcomes of these studies provide mixed results. For example, Demirer and Kutan (2006) have found no evidence of herding in the Chinese market, using CH methodology. Chan et al. (2007) did report empirical evidence of herding during periods of extreme market conditions in both Shanghai and Shenzhen B-type market. They found weaker evidence to support herding behaviour in A-type market. On the other hand, Zhou (2007) found significant evidence of herding in both Aand B-type markets. Tan et al. (2008) again found evidence of herding, but it was more evident in A-type shares market. Most of these studies with few exceptions have employed $\mathrm{CH}$ and/or CCK parametric methodology in their analysis with some variations in the way the model(s) have been estimated. For example, Chiang et al. (2012) employ rolling regression model and Chiang et al. (2013) have used Kalman filter approach to estimate time-varying parameters for the Pacific-Basin markets.

The remainder of this paper is organized as follows. Section 2 presents a review of the empirical methodology in detecting herding behaviour with particular reference to $\mathrm{CH}$ and $\mathrm{CCK}$ approaches. It also reviews some of the previous empirical findings for the Chinese market. Section 3 discusses the nonparametric methodology employed in this paper. Section 4 describes data and discussion of results. Finally, Section 5 concludes the paper.

\section{Review of literature}

In $\mathrm{CH}$ modelling of herding, cross-sectional standard deviations of individual stock returns at any given time are being regressed on two dummy variables with a constant term. The two dummies are meant to capture the extremes of market returns. It is being argued that during periods of extreme market conditions (low/high market returns) investors may herd towards the market and this can be verified empirically if the coefficients of these dummies are negative. Alternatively, CCK have proposed to use cross-sectional absolute deviations of individual returns and proposed to estimate nonlinear (quadratic) parametric model. Herding is verified when the coefficient of the quadratic term is negative and significant.

In $\mathrm{CH}$ approach, the cross-sectional standard deviations of stocks returns in relation to market return are expressed as:

$$
C S S D_{t}=\sqrt{\frac{\sum_{i=1}^{N}\left(R_{i t}-R_{m t}\right)^{2}}{N-1}}
$$

where $N$ is the number of stocks in the market, $R_{i t}$ is the observed return of stock $i$, and $R_{m t}$ is the cross-sectional average of the returns of $N$ stocks. During periods of extreme market conditions, investors may suppress their own assessment of the market and take decisions on the basis of the collective wisdom of the market. Under these circumstances, CSSD would tend to converge towards market return and will start decreasing. The empirical specification of their model is as follows: 


$$
\operatorname{CSS} D_{t}=\alpha+\beta^{L} D_{t}^{L}+\beta^{U} D_{t}^{U}+\epsilon_{t}
$$

where $C S S D_{t}$ is the cross-sectional standard deviation of individual stocks at time t. $D_{t}^{L}$ and $D_{t}^{U}$ are two dummies taking on the value of unity in the extreme lower/upper tail of the distribution of market return, respectively. ${ }^{2}$

As an alternative to $\mathrm{CH}$ approach, $\mathrm{CCK}$ proposed a nonlinear parametric relationship between dispersion and market return. Instead of using CSSD, they have proposed to use cross-sectional absolute deviations of individual stocks (CSAD), specified as:

$$
C S A D_{t}=\frac{1}{N} \sum_{i=1}^{N}\left|R_{i t}-R_{m t}\right|
$$

CCK considered a general quadratic equation to test the herding behaviour:

$$
C S A D_{t}=\alpha+\gamma_{1} R_{m t}+\gamma_{2} R_{m t}^{2}+\epsilon_{t}
$$

where negative and significant $\gamma_{2}$ would indicate herd behaviour in the market. As an alternative to the specification in Eq. (4), several papers have also employed the following specification of the model: ${ }^{3}$

$$
C S A D_{t}=\alpha+\gamma_{1}\left|R_{m t}\right|+\gamma_{2} R_{m t}^{2}+\epsilon_{t}
$$

Both $\left|R_{m t}\right|$ and $R_{m t}^{2}$ on the right hand side of the equation is based on the rationale that a linear relationship between CSAD and $R_{m t}$ is expected under normal market conditions. However, under extreme market stress, investors are likely to herd around the average market consensus, implying a nonlinear relationship between CSAD and $R_{m t}$.

Several research papers have examined and reported herding trends in Chinese capital markets and have employed the basic framework of $\mathrm{CH}$ and $\mathrm{CCK}$. For instance, Demirer and Kutan (2006) have found no evidence of herding employing firm and sector-level data. Tan et al. (2008) also report herding under both low and high extreme market return conditions; however, results of herding in A-type market was more compelling. Chiang et al. (2010) employ quantile regressions to examine herd behaviour in the Chinese stock markets and found strong evidence of herding in A- and B-type stock markets. Fu (2010) uses state-space model and found herding during lower extreme values of market return. More recently, Chiang et al. (2012) have used rolling regression method to estimate herding equations. They found evidence of herding in both markets and show the herd behaviour is correlated to global markets as well. Yao et al. (2014) have also recently reported herding evidence in the Chinese markets. They have found more significant evidence in B-type market. ${ }^{4}$ Furthermore, they have

\footnotetext{
2 The threshold values of extreme market conditions are both arbitrary and subjective in nature (See Chiang et al. (2012), Celik (2013))

3 For example, Belhoula and Naoui (2011), Chiang et al. (2013)

${ }^{4}$ However, their sample of B market also includes period before 2001 when only foreign investors could do the trading in this market.
} 
Table 1 Previous empirical studies on herding behaviour at the Chinese capital markets only

\begin{tabular}{|c|c|c|c|}
\hline Author(s) & Sample & Method & Result(s) \\
\hline Demirer and Kutan (2006) & 1999-2002 & $\mathrm{CH}$ method & Herding does not exist \\
\hline Tan et al. (2008) & 1994-2003 & CCK method & $\begin{array}{l}\text { Herding in both upper and } \\
\text { lower extremes of } R_{m t}\end{array}$ \\
\hline Chiang et al. (2010) & 1996-2007 & $\mathrm{CCK}$ and quantile regression & $\begin{array}{l}\text { Herding in A market (both } \\
\text { upper and lower extreme of } \\
R_{m t} \text { ) } \\
\text { Herding in B market (only } \\
\text { upper extreme of } R_{m t} \text { ) }\end{array}$ \\
\hline Fu (2010) & 2004-2009 & $\mathrm{CH}$ and $\mathrm{CCK}$ methods & $\begin{array}{l}\text { Herding is more dominant at } \\
\text { the lower extreme of } R_{m t}\end{array}$ \\
\hline Chiang et al. (2012) & $1996-2000$ & $\begin{array}{l}\mathrm{CH} \text { and } \mathrm{CCK} \text { methods, using } \\
\text { rolling regressions }\end{array}$ & $\begin{array}{l}\text { Evidence of herding in both } \\
\text { Market A and Market B at } \\
\text { Industry Level }\end{array}$ \\
\hline Chiang et al. (2013) & 2001-2011 & $\mathrm{CH}$ and $\mathrm{CCK}$ methods & $\begin{array}{l}\text { Strong evidence of herding in } \\
\text { A-type market }\end{array}$ \\
\hline Yao et al. (2014) & 1999-2008 & $\mathrm{CH}$ method & $\begin{array}{l}\text { Herding evidence both in A } \\
\text { and B markets, } \\
\text { industry-level analysis }\end{array}$ \\
\hline
\end{tabular}

focused on industry-level herd behaviour. Table 1 provides a brief summary of these papers. Overall these results have been mixed with some evidence of herding in the Chinese markets.

One of the issues that we have identified earlier is about the use of parametric models in empirical studies using $\mathrm{CH}$ and $\mathrm{CCK}$ approaches. There are limited number of studies reporting results of time-varying parameters of these models. For example, Chiang et al. (2012) have employed rolling regression technique to analyse herd behaviour in the Chinese markets, at industry level. An interval of one year has been used to estimate varying parameters of the model. Similarly, Celik (2013) has reported herd behaviour results for both the developed and emerging stock markets using quantile regression analysis. The model is estimated for each quantile using $1 \%$ and $5 \%$ criterion. Although employment of rolling regression and quantile regression models do address the issue of a priori restrictions imposed in the traditional modelling, the choice of the size of windows is constraint by dividing the sample into some sub-samples. In this paper, we have used kernel regression model which imposes no such restrictions on the model. Furthermore, we have used bootstrapping technique to estimate the confidence bands of the underlying varying parameters to establish herd behaviour. ${ }^{5}$ To the best of our knowledge, none of these studies have utilized nonparametric kernel regression model.

\footnotetext{
5 The nonparametric kernel regression model has been shown to perform better for large datasets. By using daily returns of stocks for the Chinese markets, our sample size is large enough to get better description and significance of herd behaviour.
} 


\section{Methodology}

One of the features of methodology employed in this paper is to estimate the underlying parameters of $\mathrm{CH}$ and $\mathrm{CCK}$ models without imposing any a priori parametric restrictions. A nonparametric kernel regression has been utilized, instead, and the local gradients (slopes) with respect to market returns have been estimated. Our model takes the following general form:

$$
Y_{t}=m\left(X_{t}\right)+\epsilon_{t}=E\left(Y_{t} \mid X_{t}\right)+\epsilon_{t}
$$

where $Y_{t}$ represents the cross-sectional variations in individual stock returns to market return (CSSD or CSAD), $X_{t}$ is the market return $\left(R_{m t}\right)$, and $\epsilon_{t}$ is the error term.

A nonparametric regression of the unknown $m(x)$ in (6) has been estimated by the local linear least squares(LLLS) method. ${ }^{6}$ The LLLS estimator is specified as (Fan and Gijbels 1996; Pagan and Ullah 1999):

$$
\hat{\delta}=\left(X^{\prime} K(x) X\right)^{-1} X^{\prime} K(x) Y
$$

where $K(x)$ is a diagonal matrix of the kernel, $K_{t x}=\left(K\left(x_{t}-x\right) / h\right)$ and $h$ is the window width. ${ }^{7}$

The nonparametric kernel regression enables us to estimate the local gradients of the underlying relationship to capture the changing nature of herd behaviour without either depending on specifying subjective threshold values to determine the extreme conditions in the market (as in $\mathrm{CH}$ ) or depending on a priori parametric form of the function (as in CCK). Furthermore, the significance of the estimated conditional means, $E(Y \mid X)$, and the gradients, $\delta$, has been verified by constructing the confidence bands using bootstrapping technique.

The estimated conditional means are being plotted against market return, together with the significance bands, to see whether the expected values of CSSD or CSAD start declining around extreme tails. In $\mathrm{CH}$ modelling of herding, threshold values of extreme market returns have to be pre-defined to use the two dummy variables. Similarly in CCK modelling, evidence of herd behaviour depends on the significant value of single quadratic term in the equation.

A variety of $K$ functions have been proposed in the literature involving some decreasing function(s) of the distances of the regressor $x_{t}$ from the other values of $x$ in the bandwidth window. In this paper, an optimal Gaussian kernel and the KullbackLeibler cross-validated window width has been employed (Pagan and Ullah 1999, Hurvich et al. 1998). ${ }^{8}$

\footnotetext{
6 Yu and Jones (1997) have shown that local linear regression is a better method compared to local constant regression for estimates at the boundaries of the sample.

7 These LLLS estimators are shown to be consistent, for further details on the properties see Fan and Gijbels (1996), Pagan and Ullah (1999)

${ }^{8}$ Several other K-functions have been used, and we find that our results are robust to the choice of the K function
} 
We use the $n p$ package in $\mathrm{R}$ to estimate the nonparametric model. The confidence bands of the estimated conditional means and gradients have been estimated by employing the npplot function in the package with 50 samples Hayfield and Racine (2008). Assuming that the CSAD-CSSD data are i.i.d, we apply the bootstrapping methodology provided by Liu (1988) to construct the confidence bands around the estimated parameters. It is important to note that the bootstrap methodology admits the heteroskedasticity in data Hayfield and Racine (2008). These estimated bands are being used, with statistical significance, to establish herd behaviour under the extreme market conditions in the differentiated markets.

\section{Data and results}

Herd behaviour has been examined and analysed in the Chinese capital markets for three different samples.

1. Market A It consists of daily returns of individual stocks on SHSZ300 Index between January 2003 and August 2014. There are 300 different A-type equities quoted on either Shanghai or Shenzhen Stock Exchanges that form this index. It enables us to examine herd behaviour of the local investors only.

2. Market $B$ We draw another sample by looking at the returns of all of the B-type stocks in Shanghai and Shenzhen Stock Exchanges over the same period (20032014). Market B consists of both the local and international investors. There are 104 different B-type equities quoted on either Shanghai or Shenzhen Stock Exchange.

3. Market A (Pre-2001) Our third sample consists of A-type stocks over period of January 1992 to February 2001. The stocks in this sample are also traded solely by local investors. This sample along with the next one allows us to distinguish between the impact of different investor groups on the return behaviour of stocks.

4. Market B (Pre-2001) Finally, our forth sample involves B-type stocks over period of January 1992 to February 2001. In this pre-2001 sample, only the foreign investors were allowed to trade.

We calculate CSSD and CSAD values for all three samples to examine the differences in her behaviour, if any.

The daily returns of individual stocks are calculated as $R_{i, t}=\left(P_{i, t}-P_{i, t-1}\right) /\left(P_{i, t-1}\right)$ where $P_{i, t}$ is the adjusted closing price level of the individual equity $i$ on a given day $t$. All of the adjusted closing prices have been collected from the Bloomberg Terminal. The descriptive statistics can be found in Table 2. The average of CSSD is larger that CSAD average in all three cases. ${ }^{9}$ The difference in the maximum and minimum values, range of data, is highest in the pre-2001 sample in the B-share market with only foreign investors. The average values do vary across different measures and types of market, however, the coefficient of variation is around 0.40 in all the cases.

\footnotetext{
${ }^{9}$ We obtain outliers for both CSSD and CSAD measures in all markets. We determine the outliers in a subjective manner and remove them from our sample. In A Market, the number of outliers with respect to CSSD measures is more pronounced compared to CSAD measures. The overall results are robust if we also remove CSAD measures on the same days we observe an outlier for CSSD measures. This problem is not evident for any other type of market.
} 
Table 2 Descriptive statistics

\begin{tabular}{|c|c|c|c|c|c|c|}
\hline & \multicolumn{2}{|c|}{ A Market } & \multicolumn{4}{|c|}{ B Market } \\
\hline & \multirow[t]{2}{*}{ CSSD } & \multirow[t]{2}{*}{ CSAD } & \multicolumn{2}{|c|}{ Pre-2001 } & \multicolumn{2}{|c|}{ Post-2001 } \\
\hline & & & CSSD & CSAD & CSSD & CSAD \\
\hline Mean & $2.27 \%$ & $1.60 \%$ & $3.19 \%$ & $2.25 \%$ & $1.72 \%$ & $1.22 \%$ \\
\hline Standard deviation & $1.02 \%$ & $0.59 \%$ & $1.56 \%$ & $0.96 \%$ & $0.62 \%$ & $0.50 \%$ \\
\hline Max & $12.48 \%$ & $5.84 \%$ & $19.09 \%$ & $10.89 \%$ & $6.25 \%$ & $5.58 \%$ \\
\hline Min & $0.77 \%$ & $0.24 \%$ & $0.00 \%$ & $0.00 \%$ & $0.51 \%$ & $0.38 \%$ \\
\hline Number of observation & 2795 & 2807 & 1563 & 1565 & 2796 & 2797 \\
\hline
\end{tabular}

It has been indicated earlier that nonparametric approach does not impose any a priori parametric restriction(s) on the underlying model. Before proceeding with our estimation of nonparametric model, a nonparametric test, proposed by Hsiao et al. (2007), has been conducted using four samples of our data. In all cases, the null hypothesis of a linear relationship has been rejected at $5 \%$ or less. ${ }^{10}$

The nonparametric model, using local linear regression model in Eq. (6), has been estimated for four samples of markets, Market A (Post-2001), Market A (Pre-2001) Market B (Post-2001) and Market B (Pre-2001). Both CSSD and CSAD have been used as dependent variables against market return, to examine herd behaviour of investors in these differentiated markets.

\section{Market A}

According to $\mathrm{CH}$ and $\mathrm{CCK}$ models, the presence of market wide herding can be verified when CSSD/CSAD show consistent declining pattern(s) under extreme market conditions. In our nonparametric approach, this can be verified by observing diminishing estimated underlying function $E(Y \mid X)$, which will also be reflected in the plots of gradients against market return. In each case the raw data, gradients and conditional means have been plotted against market return to examine herd behaviour. In order to establish the statistical significance of these results, confidence bands based on bootstrapping technique have also been shown in these graphs (Figs. 1, 2, 3, 4). ${ }^{11}$ Furthermore, the threshold values, that is, the value of the market return when herding is observed in the bear and bull market conditions, have also been reported numerically in Table $3 .^{12}$

\footnotetext{
10 We have used 'npcmstest' method in 'np' package in R Hayfield and Racine (2008). The tests were conducted both for $\mathrm{CH}$ and CCK models.

11 Both CSSD and CSAD series for all samples have been tested for unit root, and we found that all series are stationary. While applying the bootstrapping technique for nonparametric kernel regression, autocorrelation is not a serious concern when the series are stationary (Kendall 1948; Gibbons and Chakraborti 2011)

12 The Kernel nonparametric regression and confidence intervals based on bootstrapping technique allow us to examine the statistical significance of each estimated gradient. The threshold values have been identified by the sign and significance of these gradients around the extreme values of market return during extreme market conditions.
} 

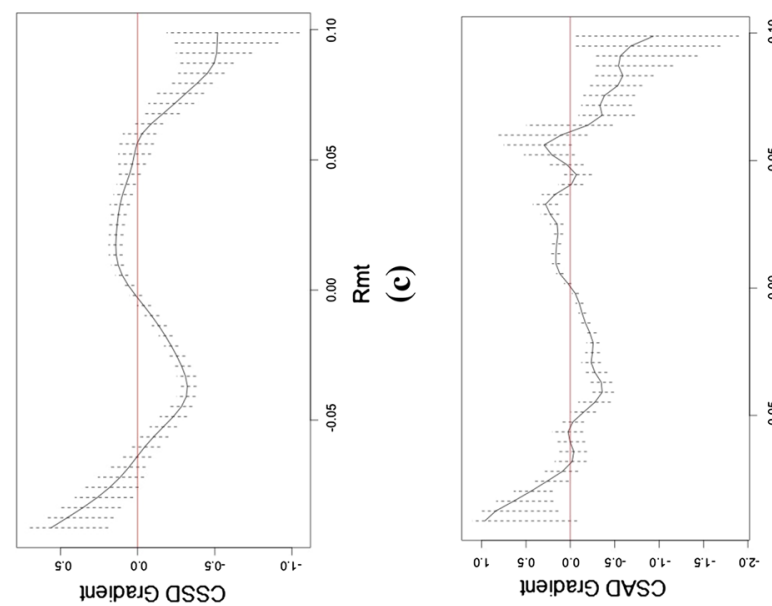


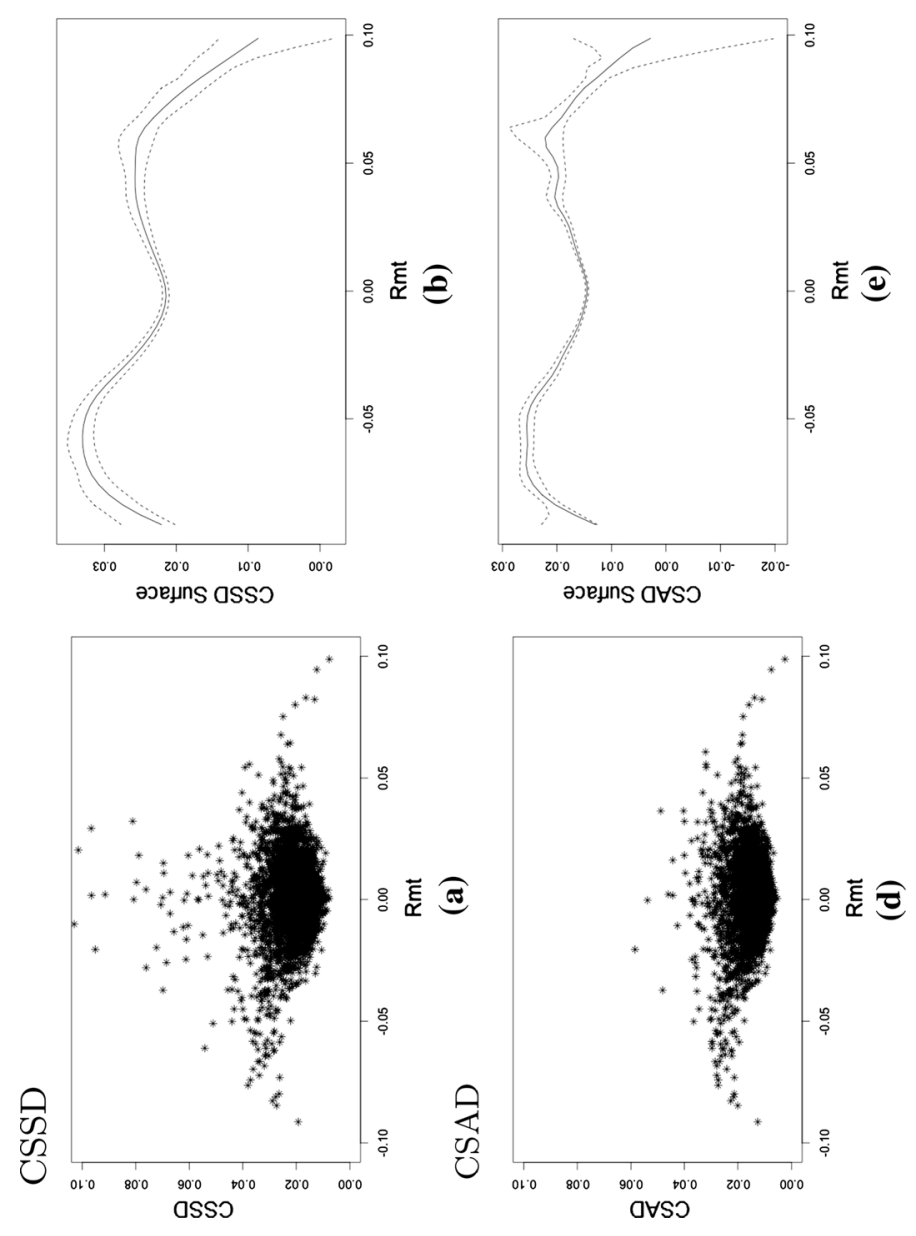

蒙过

*

$\cong$

急

$\stackrel{0}{\overline{0}}$

节产

:

ชี

ठำ

x

들

幽

ฟ

\&

플

$\because$

흥

윰

芵

표

$<$ व

可

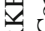

究*

$\sum$

잉 

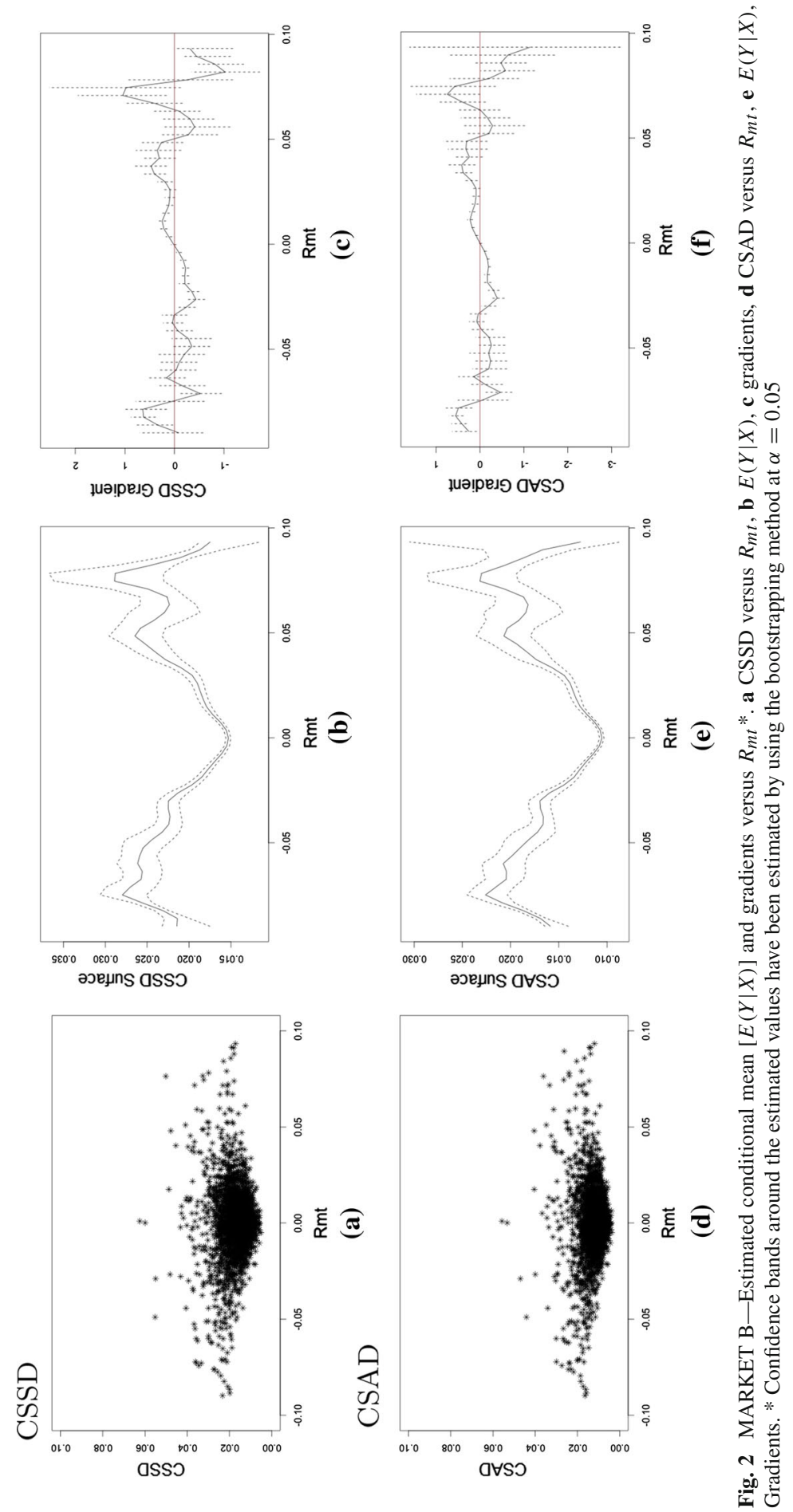

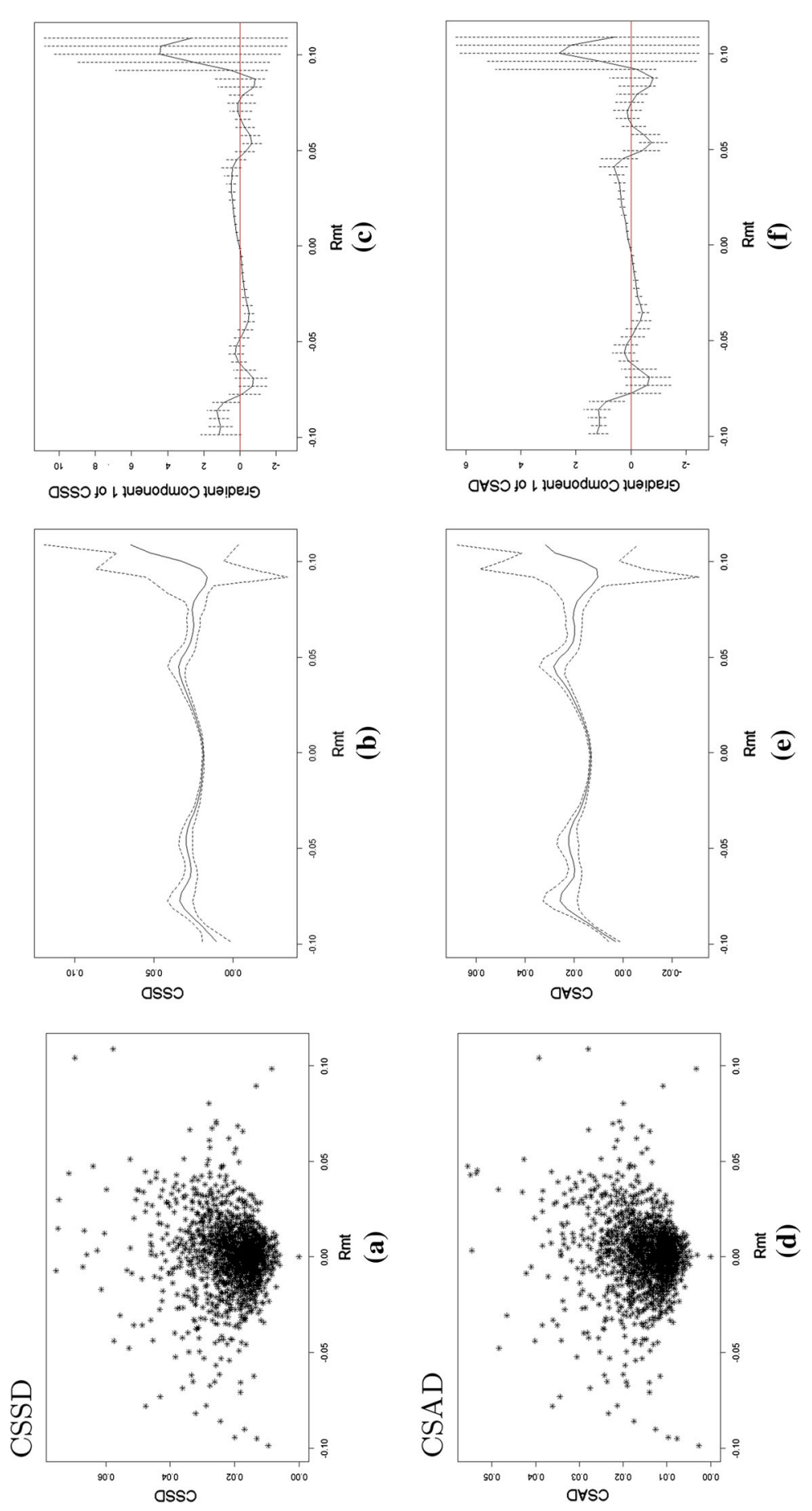

$\stackrel{\Xi}{\Sigma}$

$\stackrel{5}{5}$

要

选

产

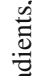

范?

कें

깅

武

-

¿

品

흘

ค

ป

\%

* I

‡.

$\approx=$

के

运 (9)

용

졿

$\underset{\underbrace{}}{\triangleq}$ 

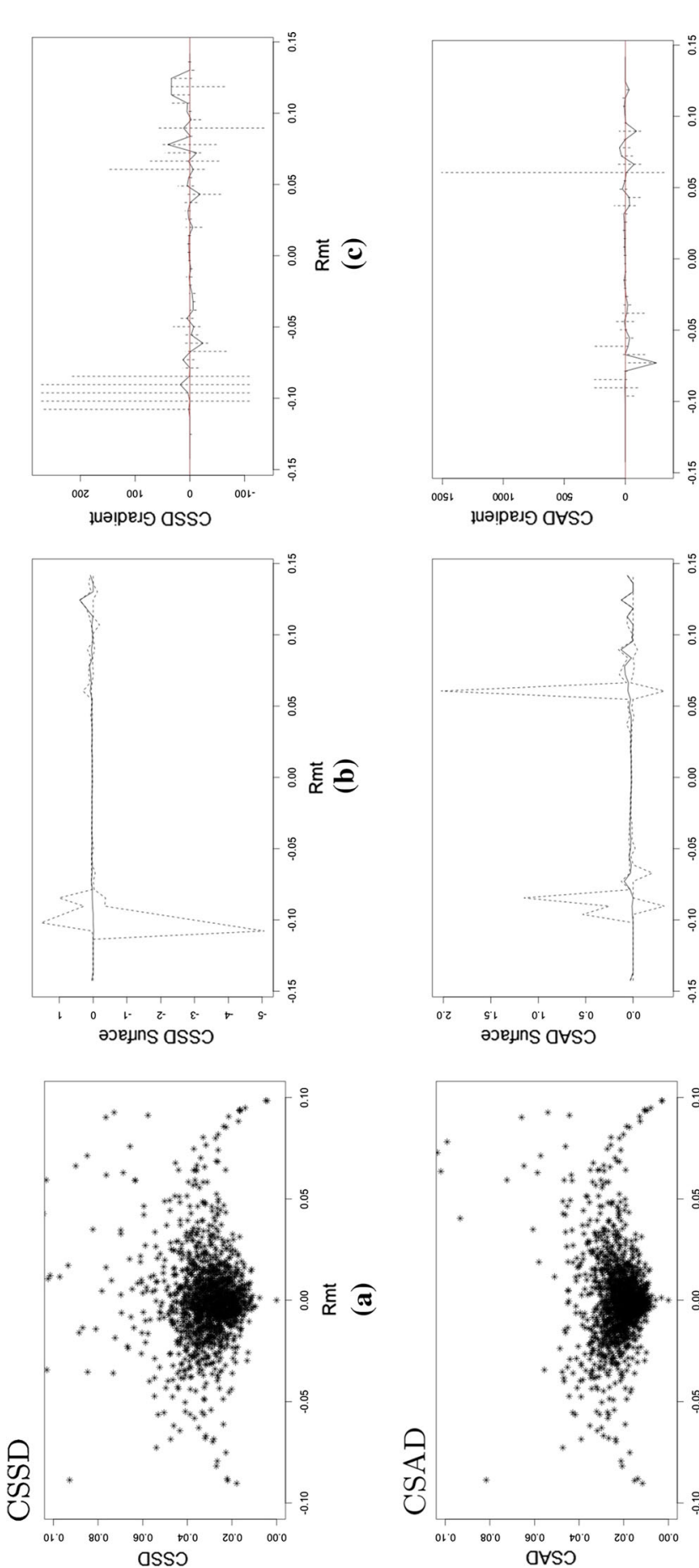

$\stackrel{0}{ٍ}$

$\tilde{3}$

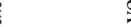

๘

$: \bar{\varepsilon} \Theta$

:

*

范

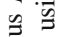

के

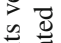

है ()

ㄱ.

疋

का

융

촗

式荥

త్ ญ

클

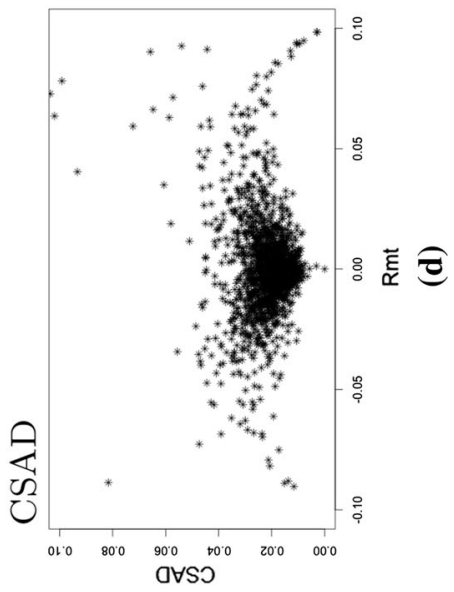

过

코

8

롱

크

雚

또 크

18 
Table 3 Nonparametric estimated gradients of $\mathrm{CH}$ model

\begin{tabular}{lcclcc}
\hline Market condition & $R_{m t}$ Cutoff point & Average gradients & Average standard error & $t$-statistics & $p$ value \\
\hline Market A-CSSD & & & & & \\
Bear & -0.064 & 0.177 & 0.075 & 2.342 & 0.01 \\
Bull & 0.058 & -0.298 & 0.108 & -2.761 & 0.01 \\
Market A-CSAD & & & & & \\
Bear & -0.070 & 0.392 & 0.141 & 2.785 & 0.01 \\
Bull & 0.064 & -0.502 & 0.198 & -2.530 & 0.01 \\
Market B-CSSD & & & & & \\
Bear & -0.076 & 0.356 & 0.186 & -1.909 & 0.05 \\
Bull & 0.078 & -0.507 & 0.286 & & 0.05 \\
Market B-CSAD & & & & 2.528 & 0.01 \\
Bear & -0.076 & 0.358 & 0.142 & -1.823 & 0.05 \\
Bull & 0.078 & -0.609 & 0.334 &
\end{tabular}

The plots of estimated conditional means of Market A noticeably show sharp declines in the surface of CSSD model (see Fig. 1). Similar results are being found in the CSAD model, but they do not appear as significant as the results of CSSD model. Furthermore, the threshold values, for the CSSD model, show that the herd behaviour is observed around 6\% of the market return on either sides of the tails (See Table 3). The results of CSAD model also imply similar values for threshold levels. The average values of the estimated gradients below (falling market) and above (rising market) threshold values do not suggest symmetrical responses of investors. For example, in the CSSD model, the average of the gradients in the falling market is 0.177 as opposed to -0.298 during the rising market (See Table 3 ). ${ }^{13}$

\section{Market B}

The examination of plots of estimated conditional means of Market B reveals mixed results of significance. The CSSD model shows significant herding during rising market conditions, and the results during falling conditions are not as significant. The threshold values are over $7.5 \%$ on either side (See Table 3). Again the responses are not found to be symmetrical. The average of gradients below (falling market) and above (rising market) is 0.356 and -0.507 , respectively (See Table 3). The CSAD model depicts different behaviour of herding. It shows significant herd behaviour during falling market (see Fig. 2). Overall we may conclude that the herd behaviour in Market A is both highly significant and observed on the either tail. The results in Market B, on the other hand, show some partial evidence of herd behaviour.

Finally, the results of our model for the B-type stocks during pre-2001 period are shown in Fig. 4). During this period, only foreign investors could trade in this market. Both the plots of the estimated function and the gradients were found to be insignificant.

\footnotetext{
13 The averages of estimated gradients during falling and rising market conditions, together with their respective statistical significances, have been reported.
} 
However, for the same time period the results of A-type (pre-2001 sample), where only local investors could trade, show significant presence of herd behaviour (Fig. 3). Demirer and Kutan (2006) also test the presence of herd period in the Chinese stock market during 1999-2002 periods without differentiating between A-type and B-type stocks but did highlight the importance of doing future work on these lines. Using both sector-level and industry-level data, they did not find any evidence of herd behaviour. Our results, on the other hand, did find strong herd behaviour in A-type stocks and further endorse the notion that differences in the characteristics of investors may explain these results.

CSAD have also been regressed against absolute market rate of return $\left|R_{m t}\right|$, using the local linear regression model in Eq. 6. This way, the herding in both extreme markets is merged together and the aggregate effect can be observed. In Fig. 5, it can be seen that estimated conditional expectations of CSAD in Market A clearly reveal herd behaviour during extreme market conditions. This is also supported by the plot of gradients against the market returns (see Fig. 5). However, these results are only partially significant in the Market B.

One of the motivations of this paper, besides using nonparametric kernel regression, is to examine the differences in herd behaviour between local and foreign investors. The Chinese stock markets provided such an opportunity as only local investors can trade in A-type stocks. It had been argued that the local Chinese investors lack both knowledge and experience of investing in stock markets compared to foreign institutional investors and the differences in the characteristics of the investors may manifest in different herd behaviour. All the nonparametric results have suggested strong presence of herd behaviour in A-type stock market, where only local investors can trade.

In order to assess and test the robustness of these results, a number of additional estimations have been made. First, the analysis has been extended to disaggregated data of stocks in the two markets. Data on nine different sectors have been compiled, and the models have been re-run for these sectors. ${ }^{14}$ In market B, pre-2001 sample, we could not find any evidence of herding in any of the sectors. However, results of market B, post-2001 sample, do indicate that herding was present in some of the sectors. In particular, pronounced herding was found in Industrial, Materials and Utilities. In rest of the sectors, either herding was weak or was not statistically significant. In Atype stocks, where only local investors can trade, significant herding was found in all the sectors, particularly during rising market. Demirer and Kutan (2006) have also employed sector-level data for the Chinese market, but overall they did not find any significant evidence of herding. However, they strongly recommended re-examining herd behaviour in A-share and B-share markets where it is possible to differentiate between domestic and foreign investors. Tan et al. (2008) also analysed herd behaviour in the Chinese markets, employing aggregated data only, and found evidence of herd behaviour in A-share and B-share markets. However, they found more pronounced herd behaviour in A-share market during rising market conditions, which is consistent with our results.

14 See "Appendix". 


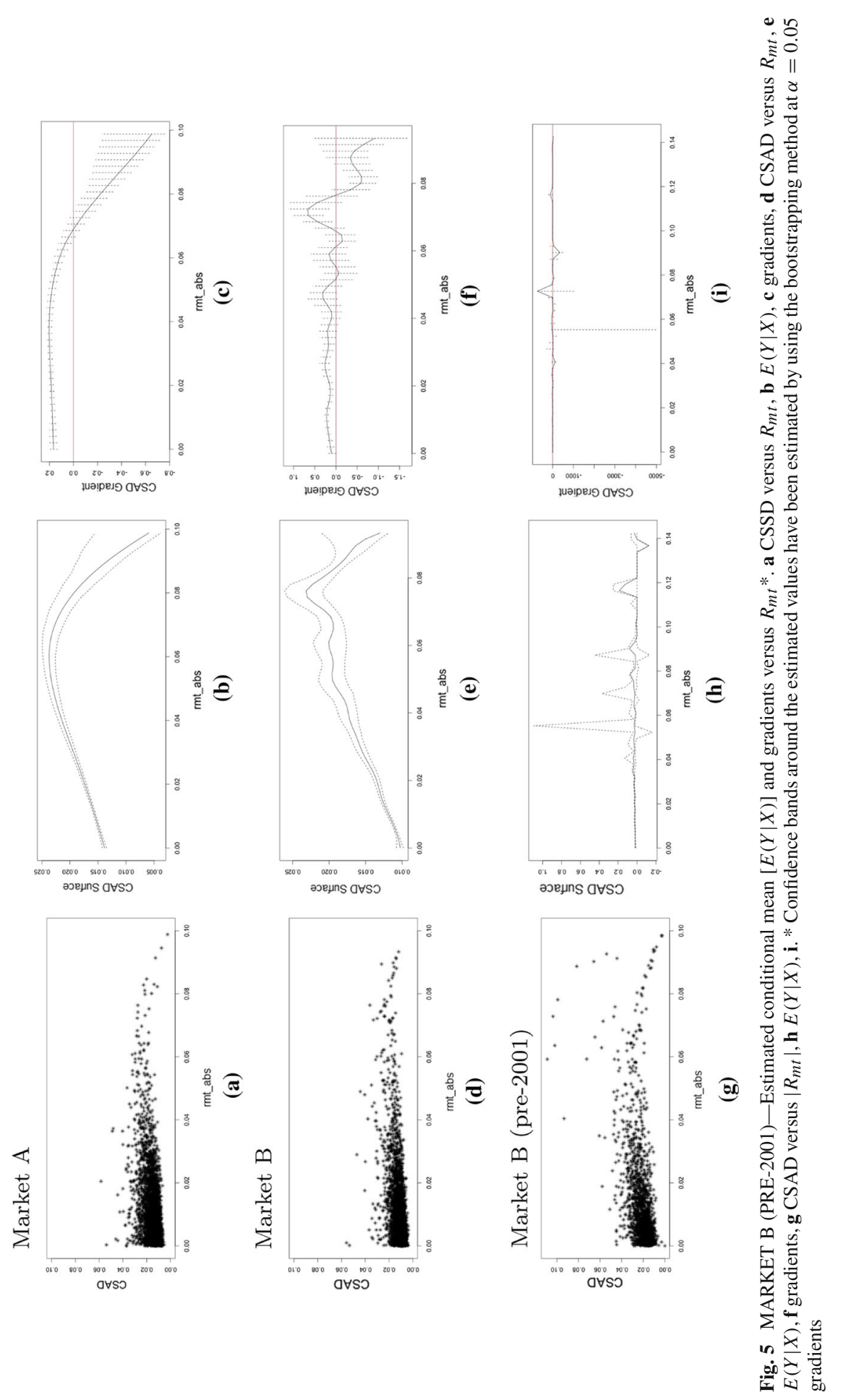


Second, dummy variable for the year 2008 has been included in all the models. The inclusion of dummy variable did not change the overall results reported in this paper.

Third, a two-stage procedure has been employed to control the effects of global factors in our analysis. In the first stage, the effects of USA market return have been removed from the market return(s) of the Chinese markets and the models have been re-estimated using the adjusted market returns. Again we found strong evidence of herd behaviour as reported in the paper. The results of the last two robustness checks have not been reported in this paper.

\section{Conclusion}

In this paper, we test herd behaviour in the Chinese capital markets following the methodology proposed by Christie and Huang (1995), Chang et al. (2000). The paper makes several contributions to the existing empirical literature on the subject. First, most of the studies following the proposed methodology ( $\mathrm{CH}$ and $\mathrm{CKK}$ ) have utilized constant coefficient parametric model(s). In this paper, we have employed nonparametric kernel regression model and have presented new evidence of dynamic herd behaviour in the Chinese capital markets. Second, the herd behaviour has been analysed across different characteristics of the investors in the Chinese market. Third both aggregated and sector-level data have been employed in our analysis.

A number of studies have previously examined herd behaviour in the Chinese capital markets, using parametric specifications based on $\mathrm{CH}$ and $\mathrm{CCK}$ approaches. The overall results of these studies have been inconclusive. The results of herd behaviour based on A-type and B-Type classifications of stocks in the Chinese market have only been provided by Tan et al. (2008), and they have found more significant herd behaviour in A-type stocks. Based on our nonparametric regression results, we have also found very strong evidence of herd behaviour in A-type stocks, where only local investors can trade. These results supported the conclusions of Tan et al. (2008) that lack of knowledge and experience of local investors may explain significant herd behaviour in A-type stocks. By de-classifying our sample to pre-2001 period, when only foreign investors could do trading in B-type stocks, we could not find any evidence of herd behaviour. This has further given support to the argument that the differences in the characteristics of investors may explain herd behaviour. These results were also robust when sector-level data have been employed. The results based on bootstrapping technique have also shown that the herd behaviour has been observed both in the rising and falling markets. This is in contrast to results of previous studies where herd behaviour has been more pronounced during rising market only.

One of the important extensions of our work would be to examine herd behaviour by making use of NP panel fixed and random effect estimators proposed by Su and Ullah (2006), Su et al. (2013). Hwang and Salmon (2004) have also proposed nonparametric standard factor model, using state-space modelling approach. This methodology can also be employed to further examine the herd behaviour across A-type and B-type stocks in the Chinese capital market. 


\section{Appendix}

\section{A Market}

CSSD

Consumer Discretionary

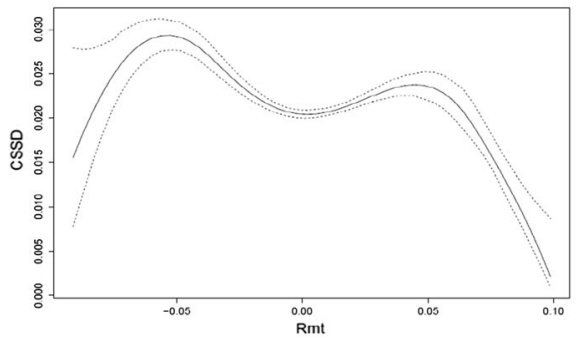

(a) $\mathrm{E}(\mathrm{Y} \mid \mathrm{X})$

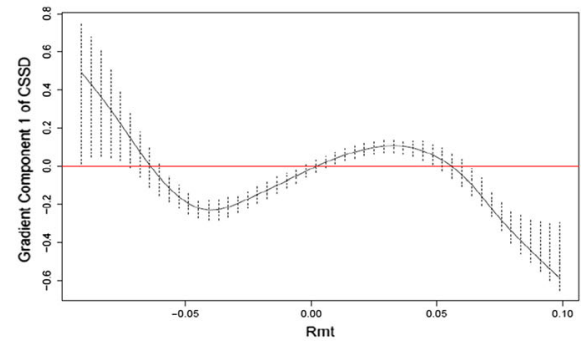

(b) Gradients

Consumer Staples

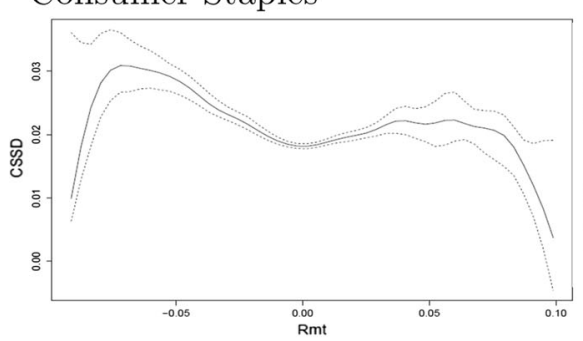

(a) $\mathrm{E}(\mathrm{Y} \mid \mathrm{X})$

Energy

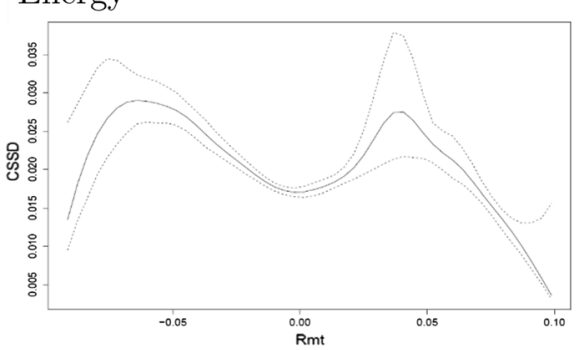

(a) $\mathrm{E}(\mathrm{Y} \mid \mathrm{X})$

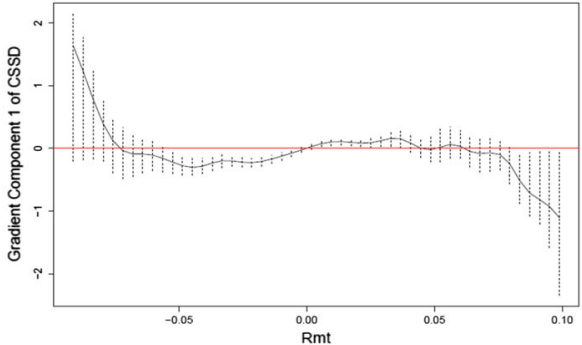

(b) Gradients

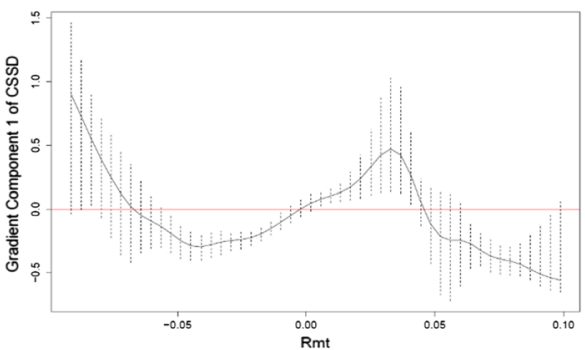

(b) Gradients 


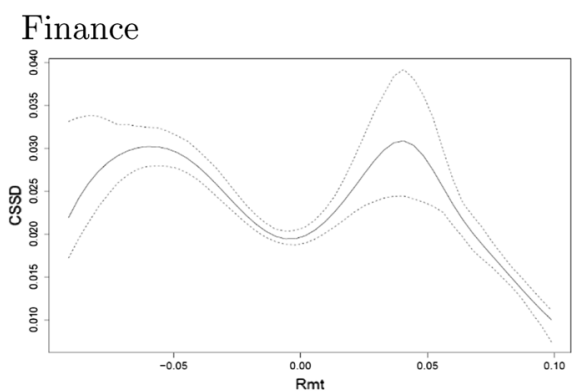

(a) $\mathrm{E}(\mathrm{Y} \mid \mathrm{X})$

\section{Health Care}

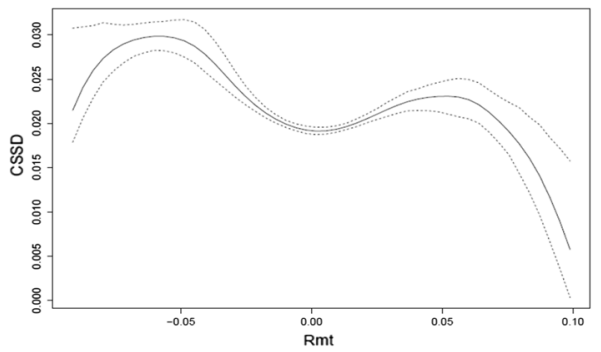

(a) $\mathrm{E}(\mathrm{Y} \mid \mathrm{X})$

\section{Industrials}

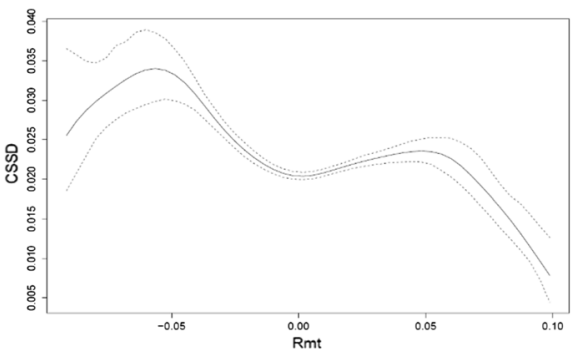

(a) $\mathrm{E}(\mathrm{Y} \mid \mathrm{X})$

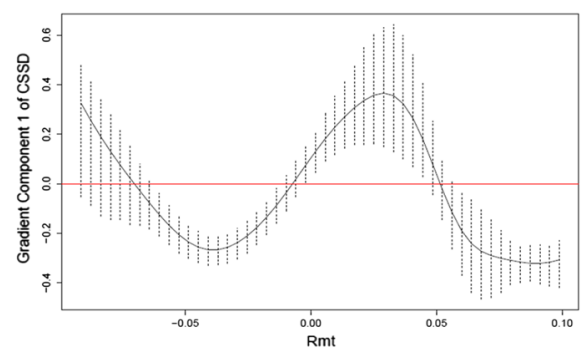

(b) Gradients

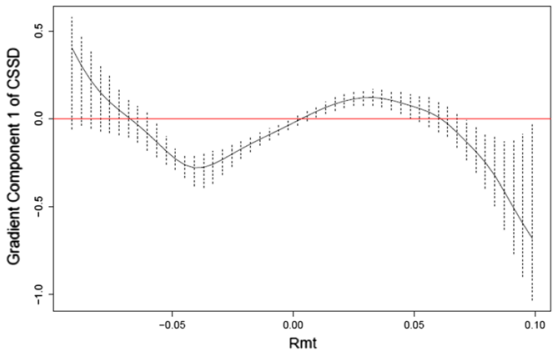

(b) Gradients

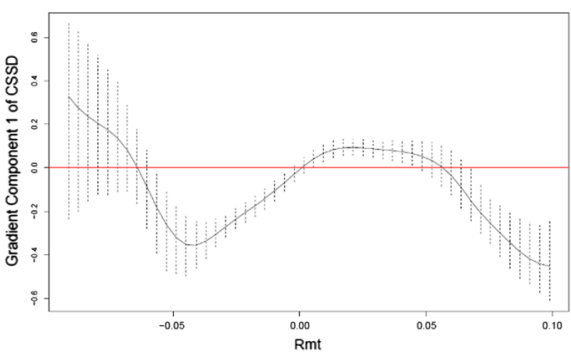

(b) Gradients 


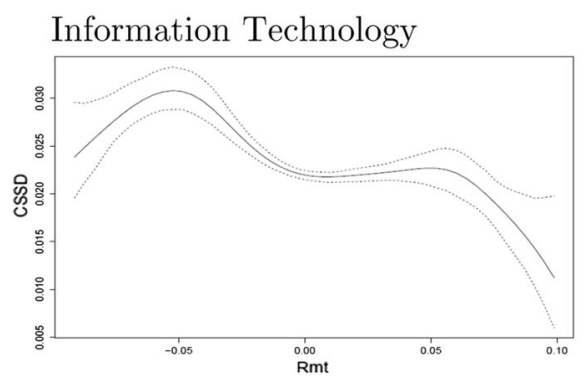

(a) $\mathrm{E}(\mathrm{Y} \mid \mathrm{X})$

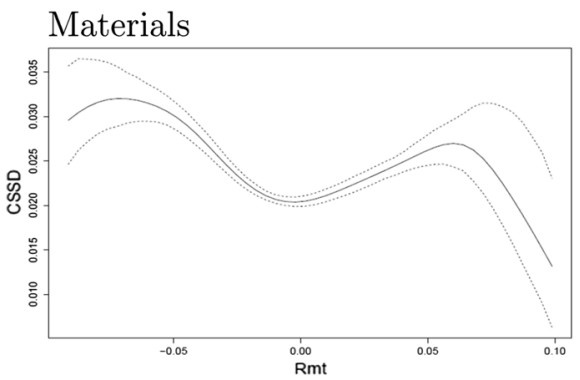

(a) $\mathrm{E}(\mathrm{Y} \mid \mathrm{X})$

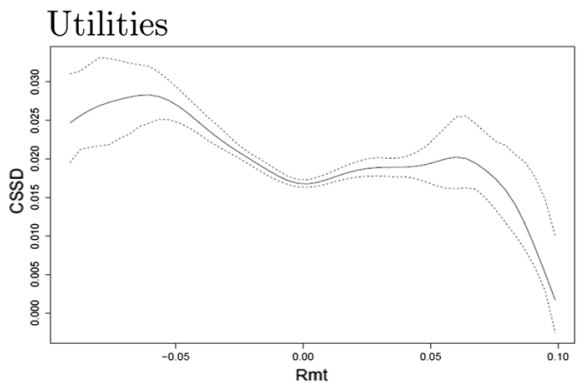

(a) $\mathrm{E}(\mathrm{Y} \mid \mathrm{X})$

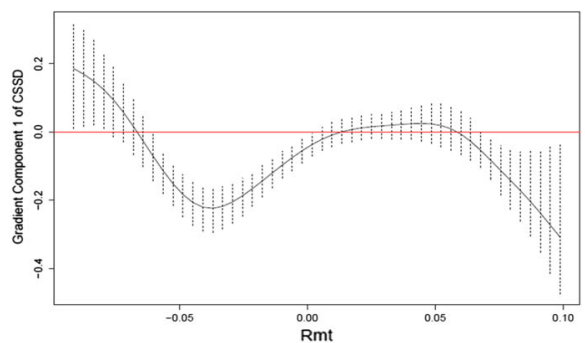

(b) Gradients

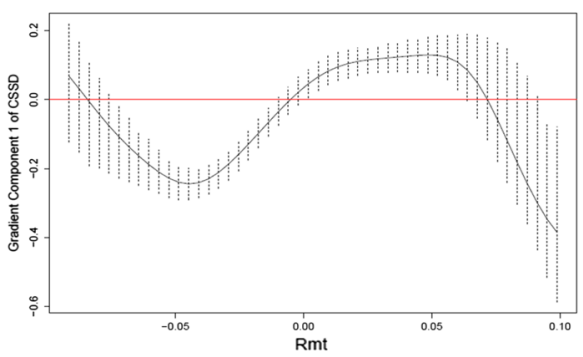

(b) Gradients

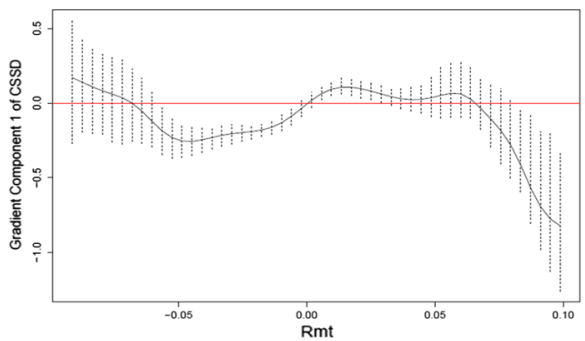

(b) Gradients 


\section{$C S A D$}

\section{Consumer Discretionary}

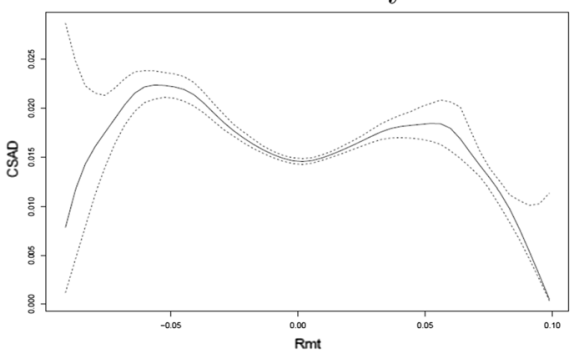

(a) $\mathrm{E}(\mathrm{Y} \mid \mathrm{X})$

Consumer Staples

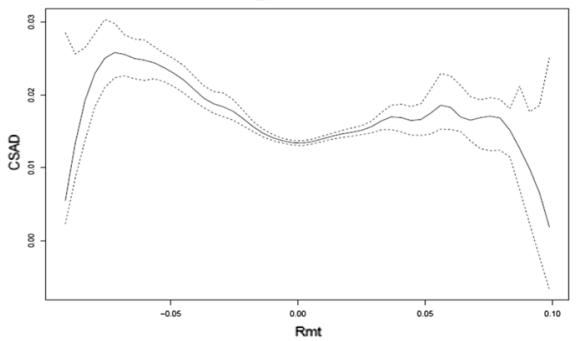

(a) $\mathrm{E}(\mathrm{Y} \mid \mathrm{X})$

Energy

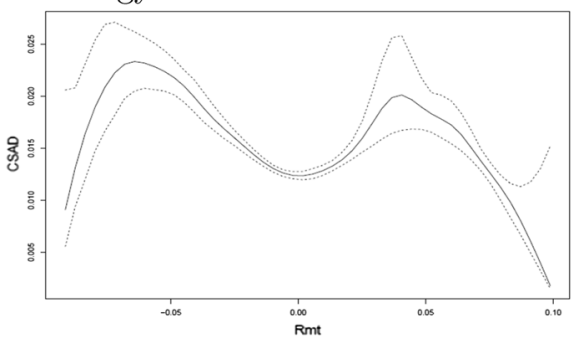

(a) $\mathrm{E}(\mathrm{Y} \mid \mathrm{X})$

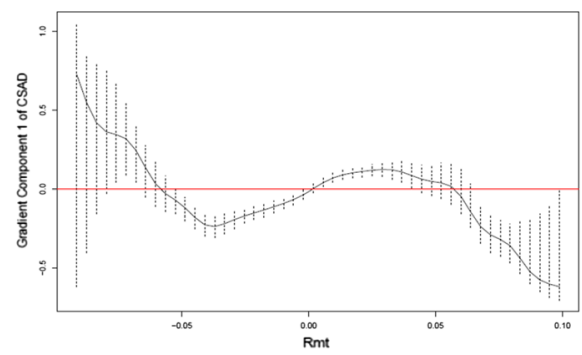

(b) Gradients

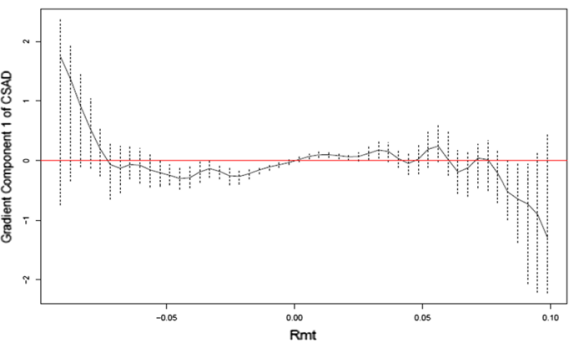

(b) Gradients

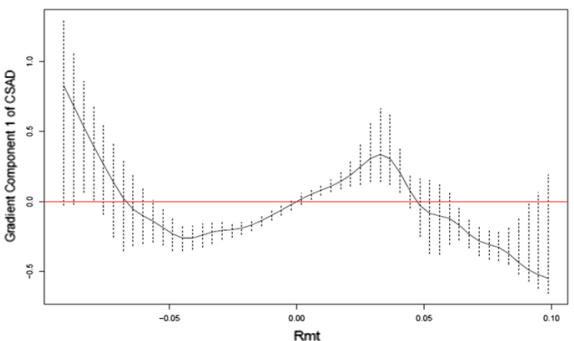

(b) Gradients 


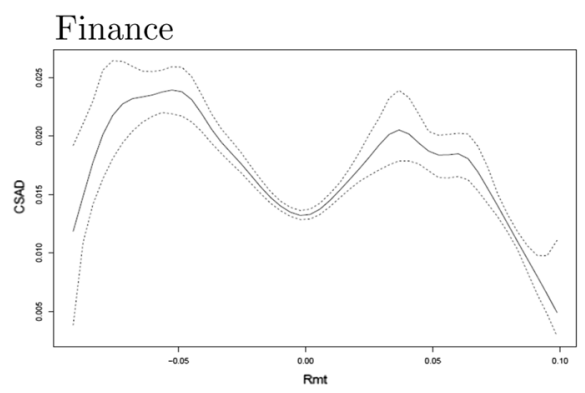

(a) $\mathrm{E}(\mathrm{Y} \mid \mathrm{X})$

\section{Health Care}

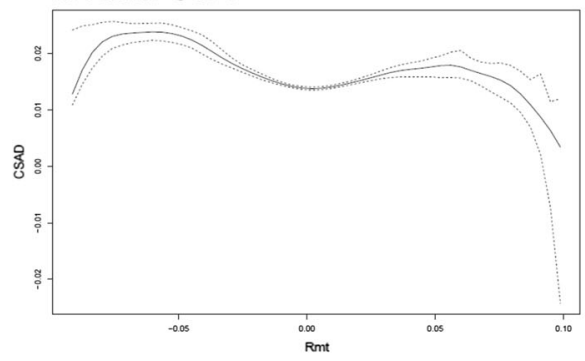

(a) $\mathrm{E}(\mathrm{Y} \mid \mathrm{X})$

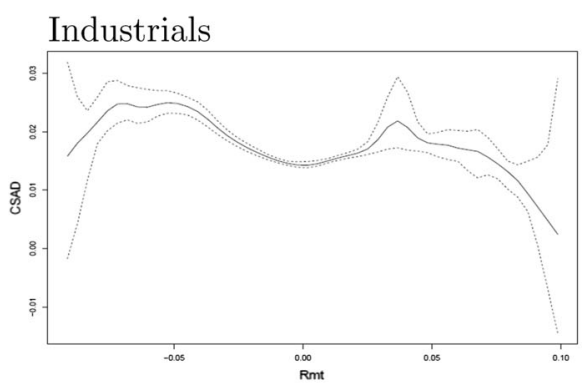

(a) $\mathrm{E}(\mathrm{Y} \mid \mathrm{X})$

Information Technology

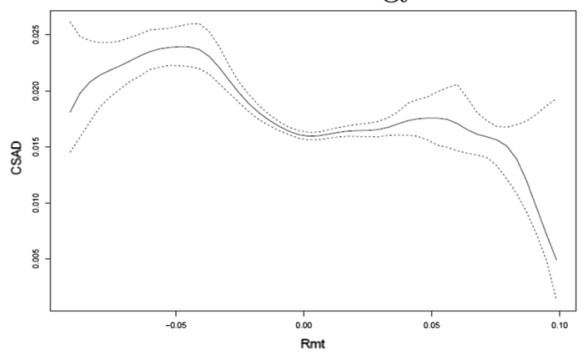

(a) $\mathrm{E}(\mathrm{Y} \mid \mathrm{X})$

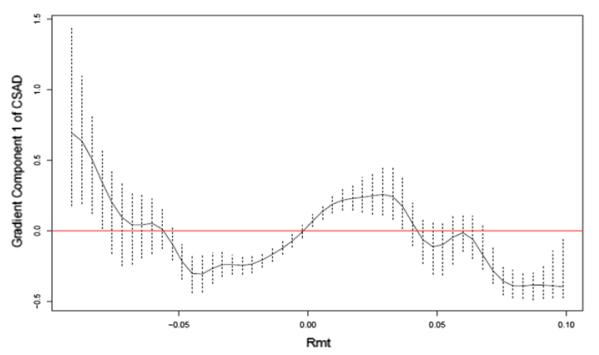

(b) Gradients

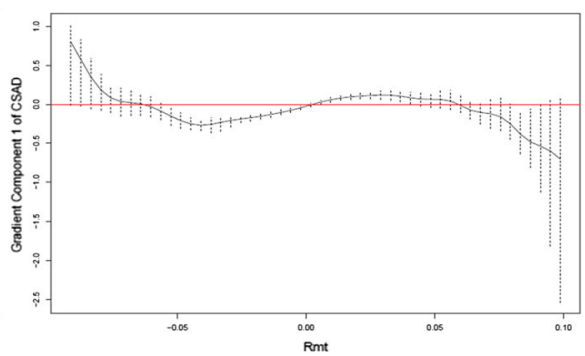

(b) Gradients

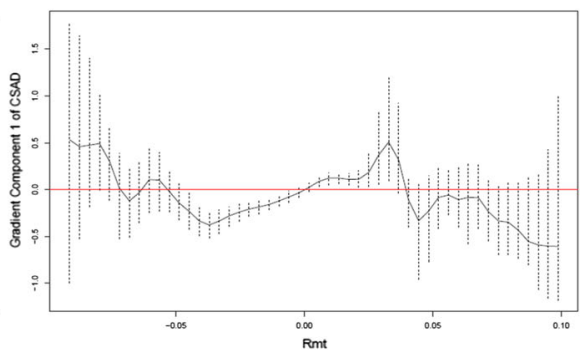

(b) Gradients

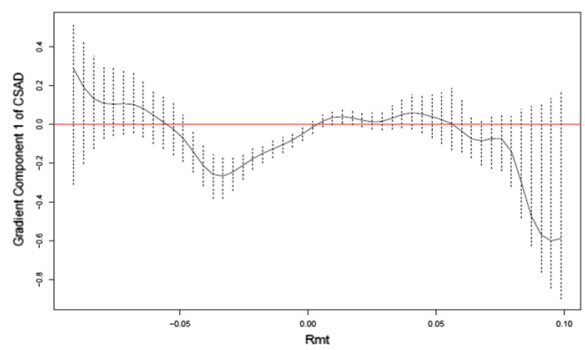

(b) Gradients 


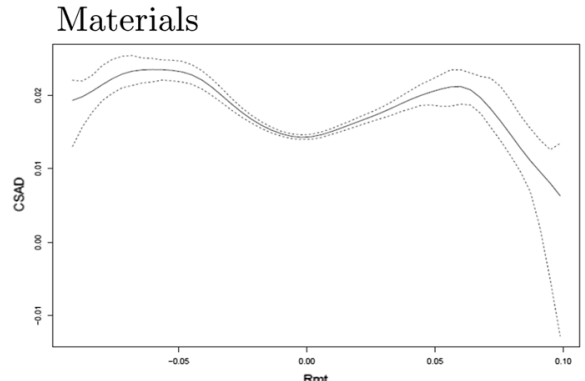

(a) $\mathrm{E}(\mathrm{Y} \mid \mathrm{X})$

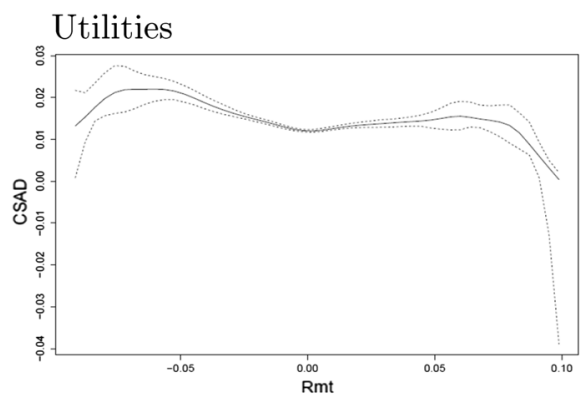

(a) $\mathrm{E}(\mathrm{Y} \mid \mathrm{X})$

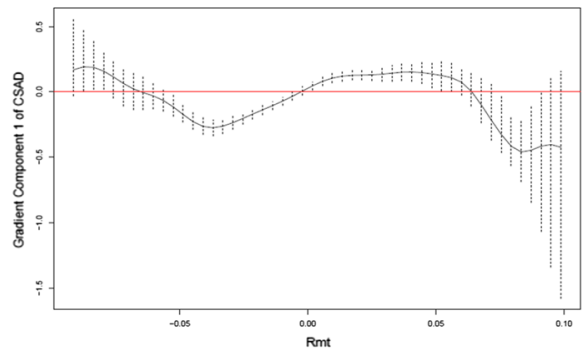

(b) Gradients

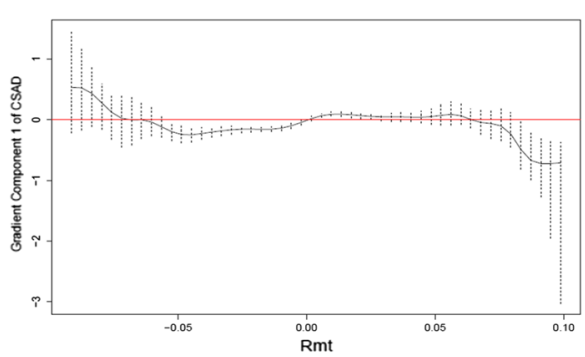

(b) Gradients

\section{B Market (Post-2001)}

\section{CSSD}

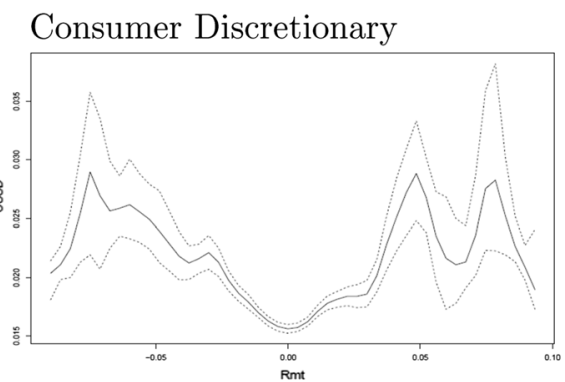

(a) $\mathrm{E}(\mathrm{Y} \mid \mathrm{X})$

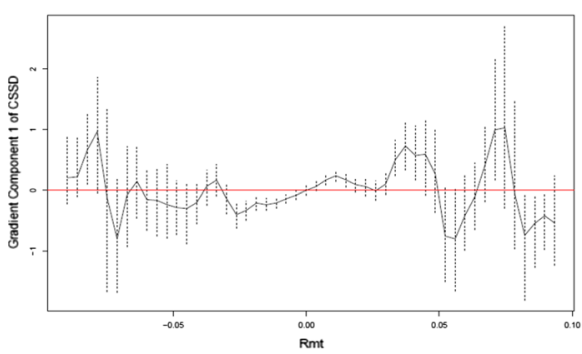

(b) Gradients 


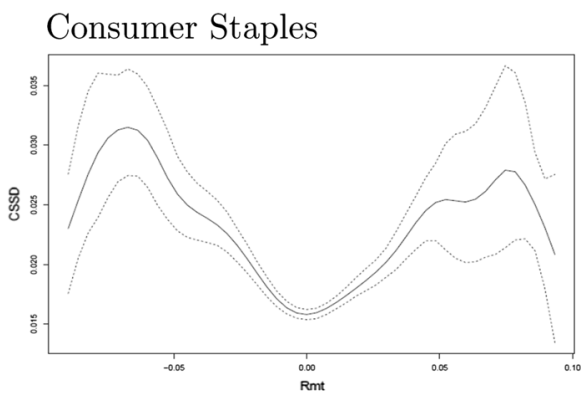

(a) $\mathrm{E}(\mathrm{Y} \mid \mathrm{X})$

\section{Energy}

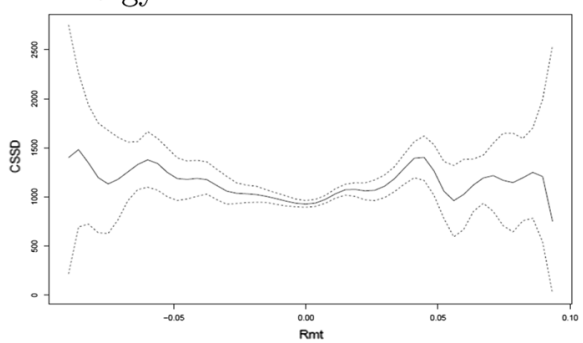

(a) $\mathrm{E}(\mathrm{Y} \mid \mathrm{X})$

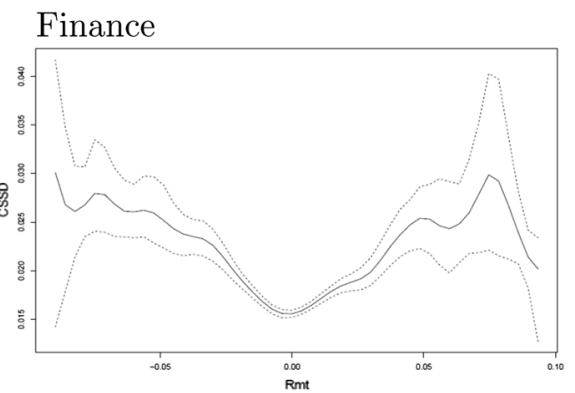

(a) $\mathrm{E}(\mathrm{Y} \mid \mathrm{X})$

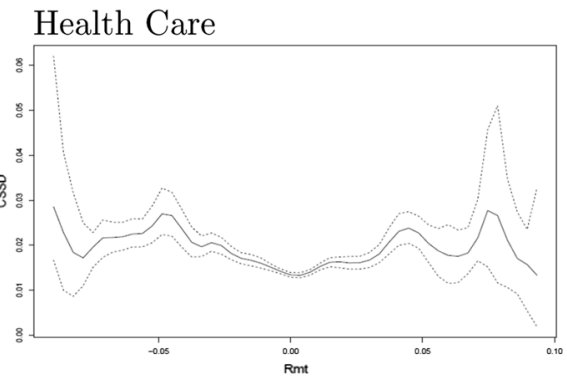

(a) $\mathrm{E}(\mathrm{Y} \mid \mathrm{X})$

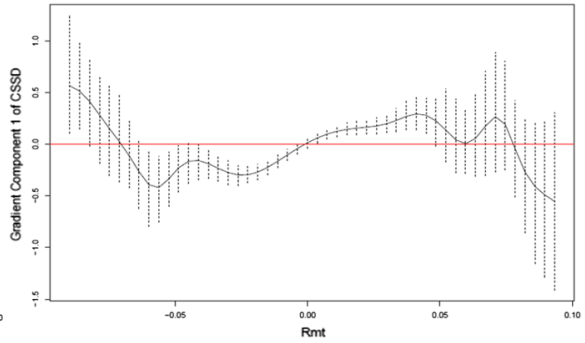

(b) Gradients

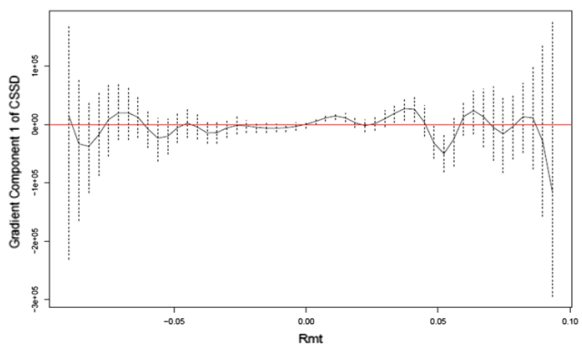

(b) Gradients

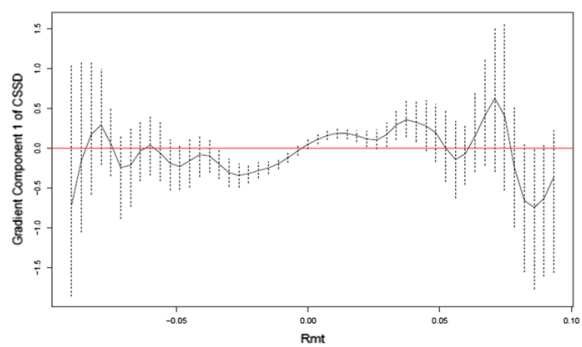

(b) Gradients

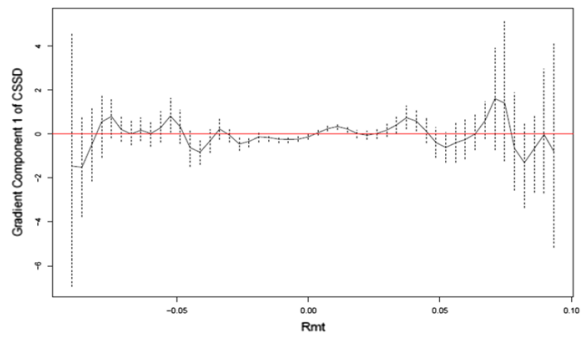

(b) Gradients 


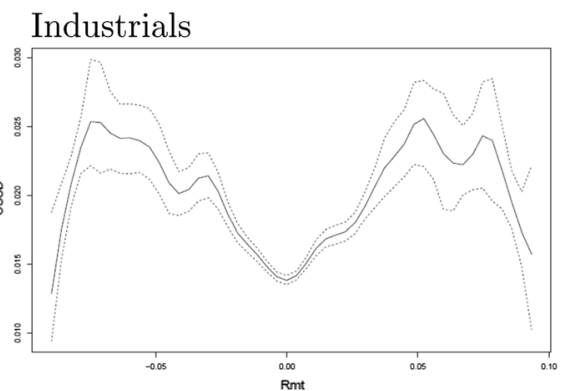

(a) $\mathrm{E}(\mathrm{Y} \mid \mathrm{X})$

Information Technology

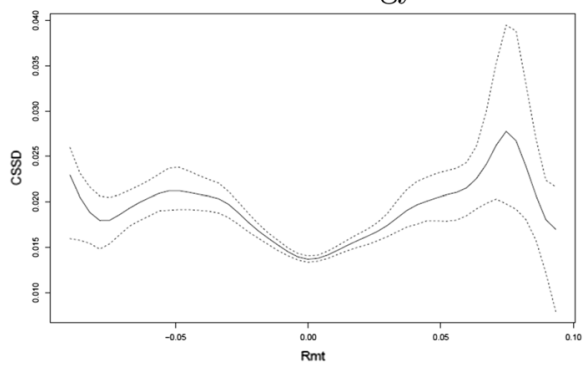

(a) $\mathrm{E}(\mathrm{Y} \mid \mathrm{X})$

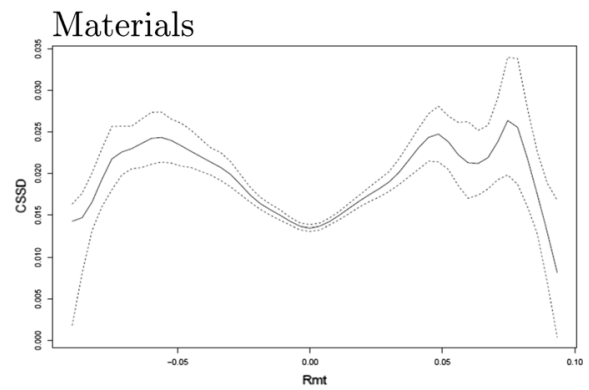

(a) $\mathrm{E}(\mathrm{Y} \mid \mathrm{X})$

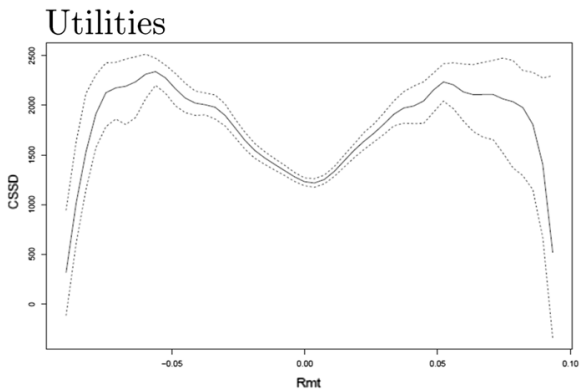

(a) $\mathrm{E}(\mathrm{Y} \mid \mathrm{X})$

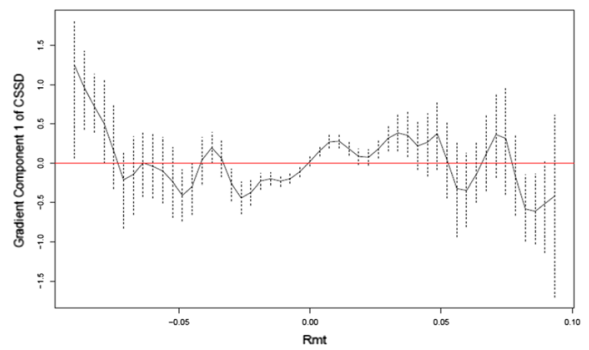

(b) Gradients

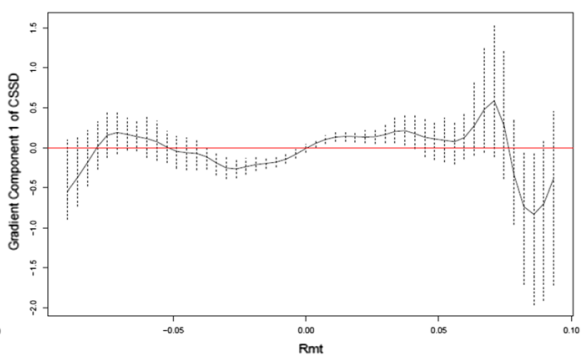

(b) Gradients

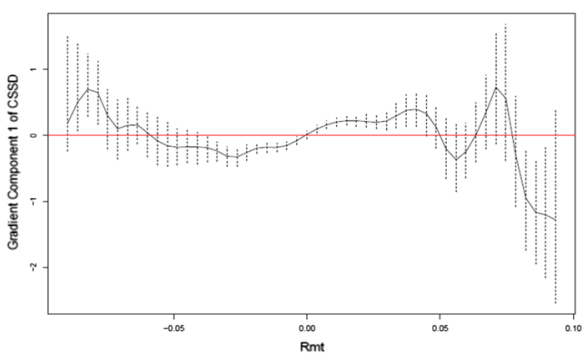

(b) Gradients

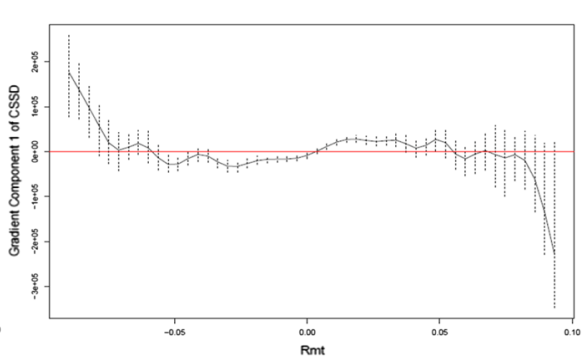

(b) Gradients 


\section{$C S A D$}

\section{Consumer Discretionary}

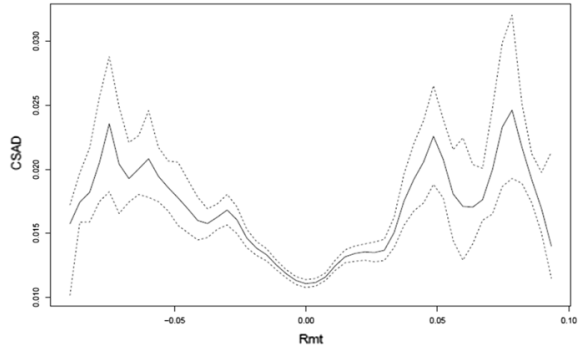

(a) $\mathrm{E}(\mathrm{Y} \mid \mathrm{X})$

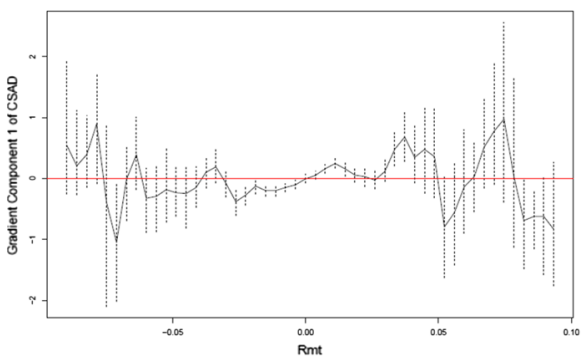

(b) Gradients

Consumer Staples

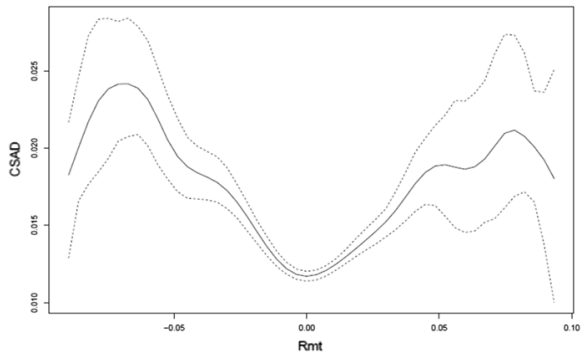

(a) $\mathrm{E}(\mathrm{Y} \mid \mathrm{X})$

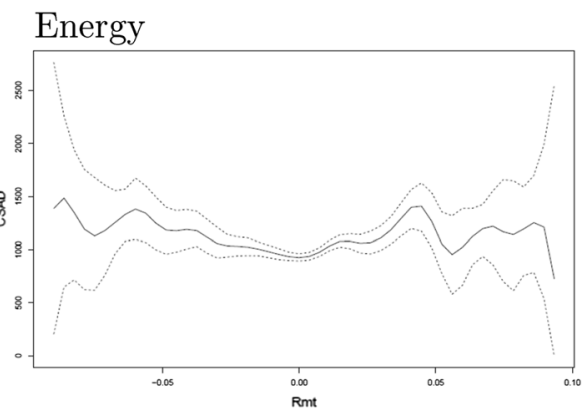

(a) $\mathrm{E}(\mathrm{Y} \mid \mathrm{X})$

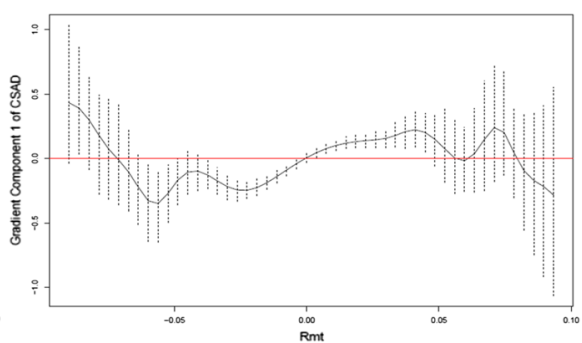

(b) Gradients

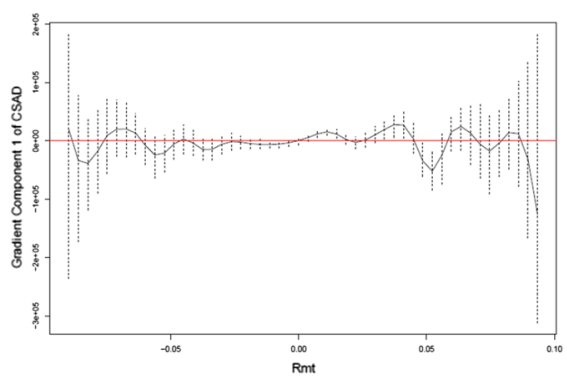

(b) Gradients 


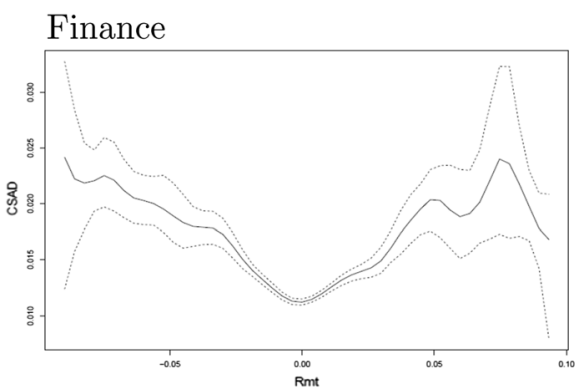

(a) $\mathrm{E}(\mathrm{Y} \mid \mathrm{X})$

Health Care

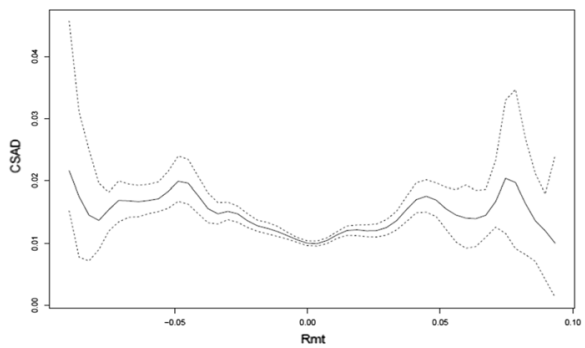

(a) $\mathrm{E}(\mathrm{Y} \mid \mathrm{X})$

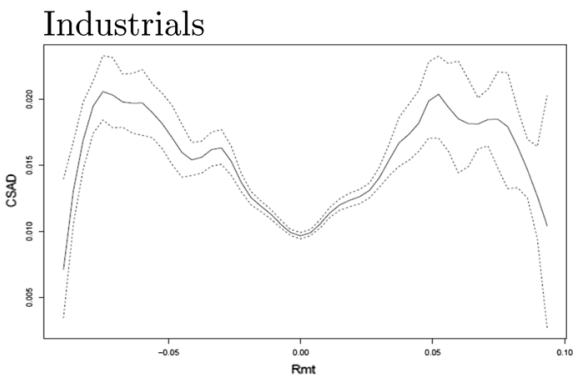

(a) $\mathrm{E}(\mathrm{Y} \mid \mathrm{X})$

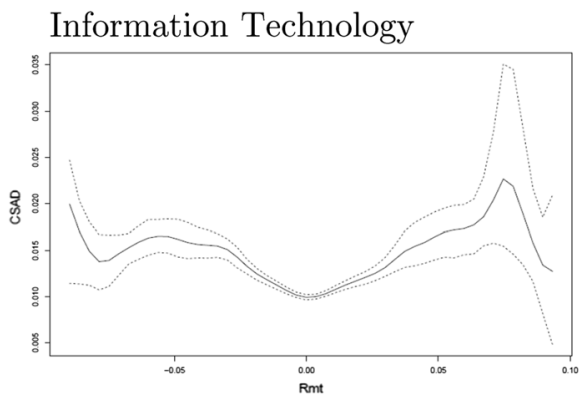

(a) $\mathrm{E}(\mathrm{Y} \mid \mathrm{X})$

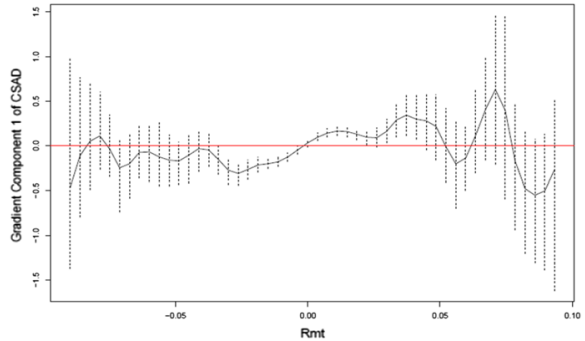

(b) Gradients

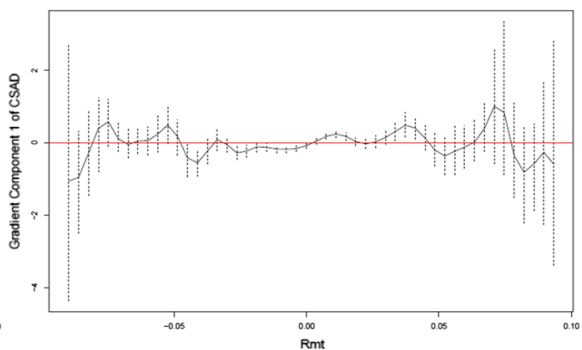

(b) Gradients

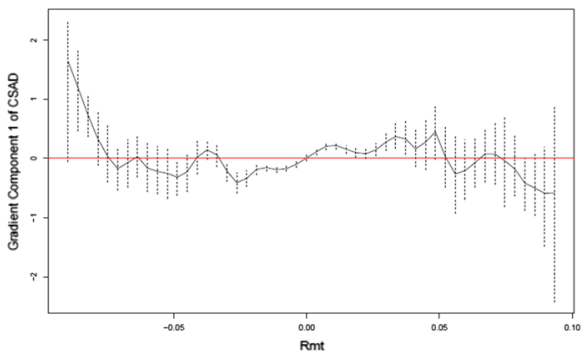

(b) Gradients

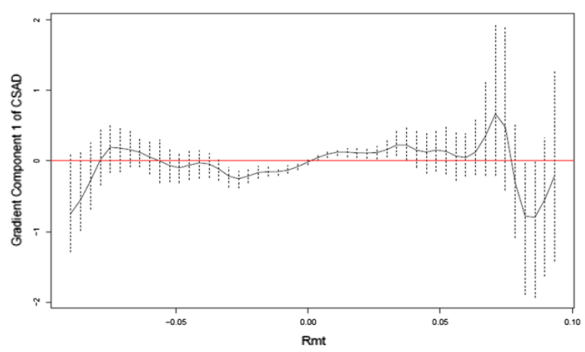

(b) Gradients 


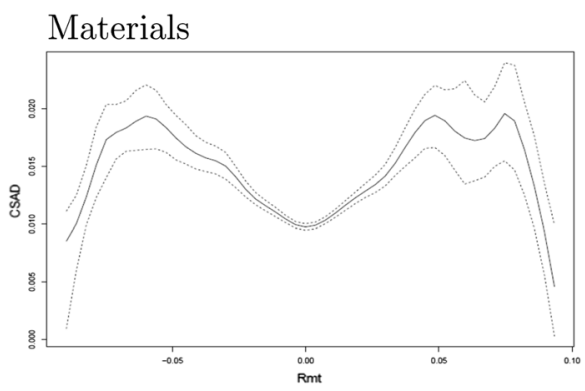

(a) $\mathrm{E}(\mathrm{Y} \mid \mathrm{X})$

\section{Utilities}

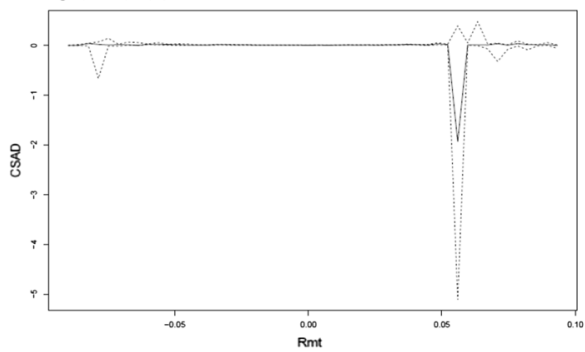

(a) $\mathrm{E}(\mathrm{Y} \mid \mathrm{X})$

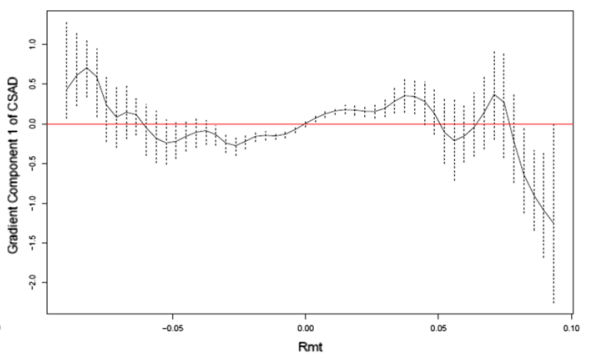

(b) Gradients

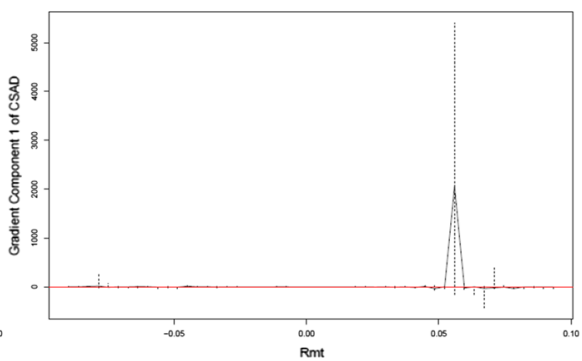

(b) Gradients

\section{B-Market (Pre-2001)}

\section{CSSD}

\section{Consumer Discretionary}

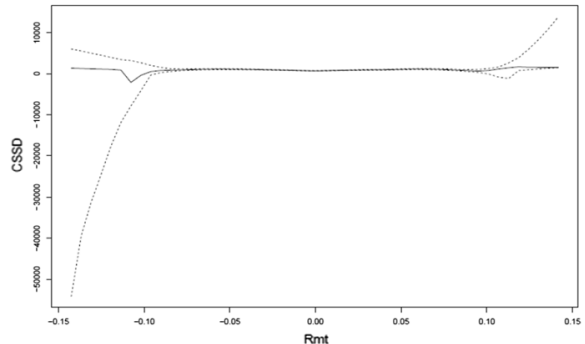

(a) $\mathrm{E}(\mathrm{Y} \mid \mathrm{X})$

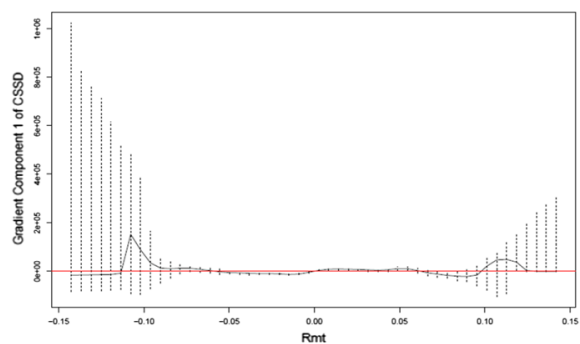

(b) Gradients 


\section{Consumer Staples}

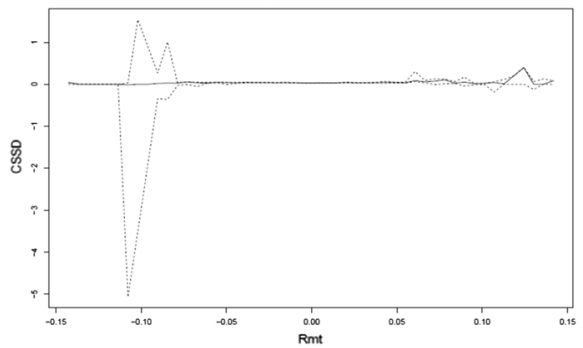

(a) $\mathrm{E}(\mathrm{Y} \mid \mathrm{X})$

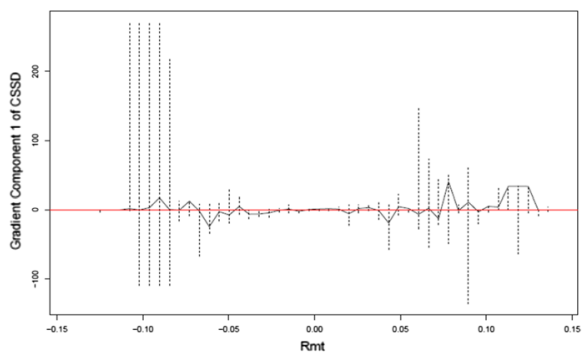

(b) Gradients

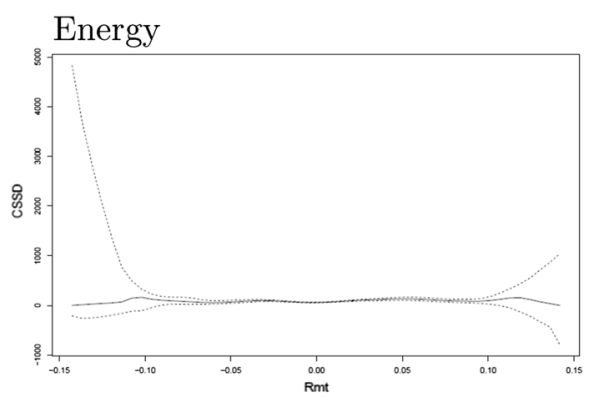

(a) $\mathrm{E}(\mathrm{Y} \mid \mathrm{X})$

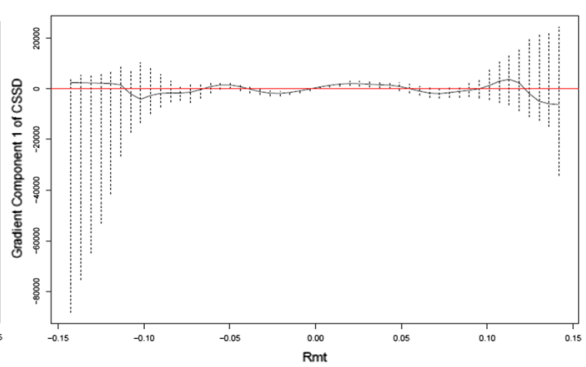

(b) Gradients

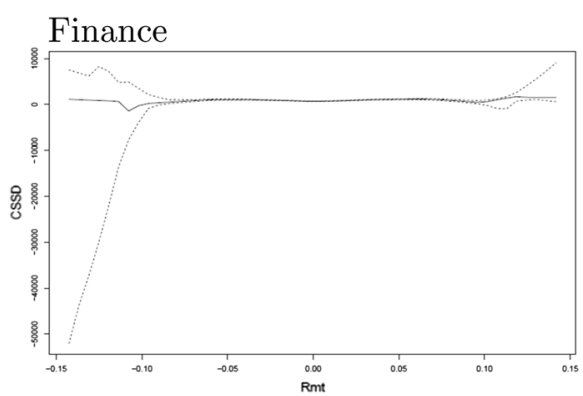

(a) $\mathrm{E}(\mathrm{Y} \mid \mathrm{X})$

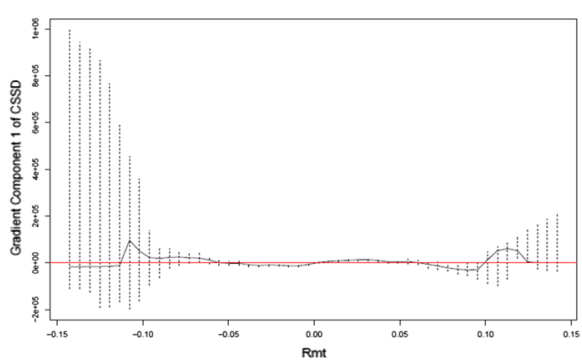

(b) Gradients

\section{Health Care}

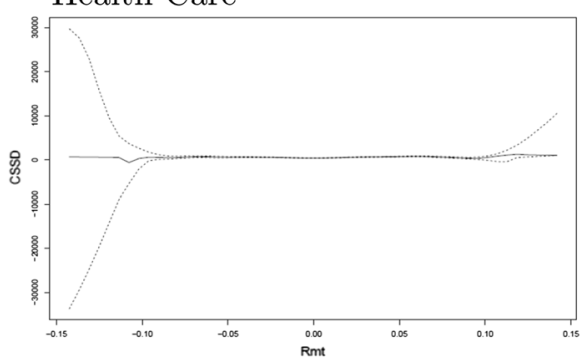

(a) $\mathrm{E}(\mathrm{Y} \mid \mathrm{X})$

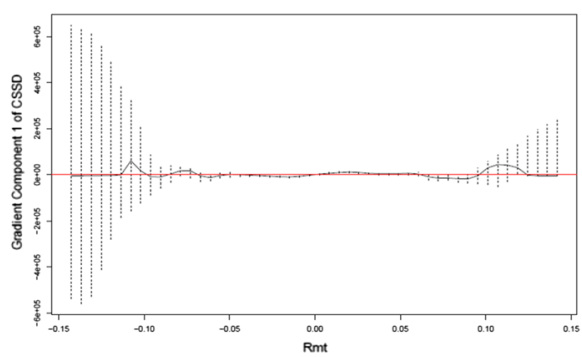

(b) Gradients 


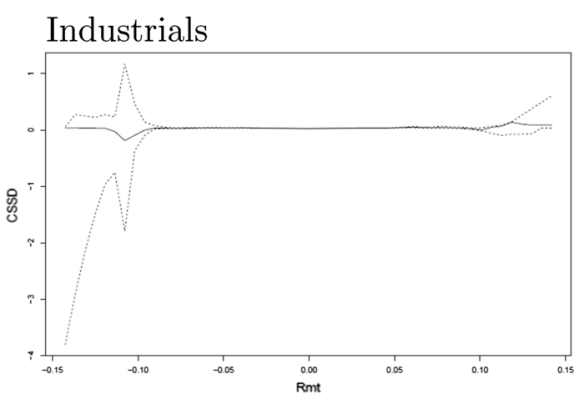

(a) $\mathrm{E}(\mathrm{Y} \mid \mathrm{X})$

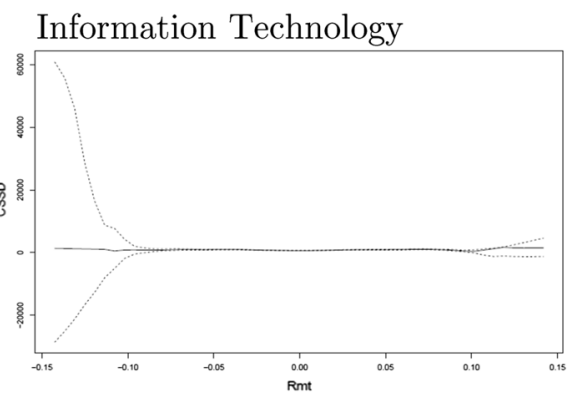

(a) $\mathrm{E}(\mathrm{Y} \mid \mathrm{X})$

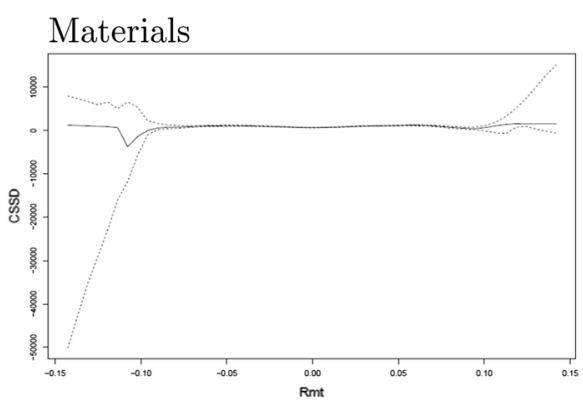

(a) $\mathrm{E}(\mathrm{Y} \mid \mathrm{X})$

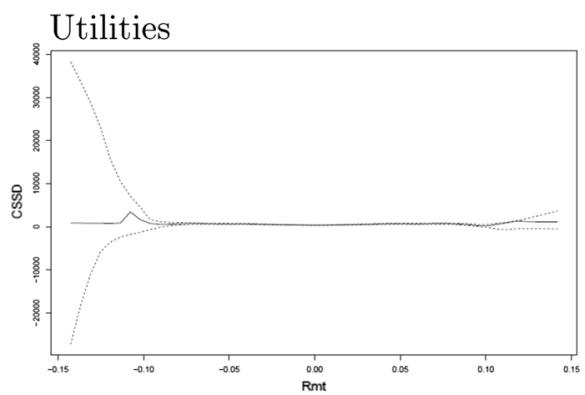

(a) $\mathrm{E}(\mathrm{Y} \mid \mathrm{X})$

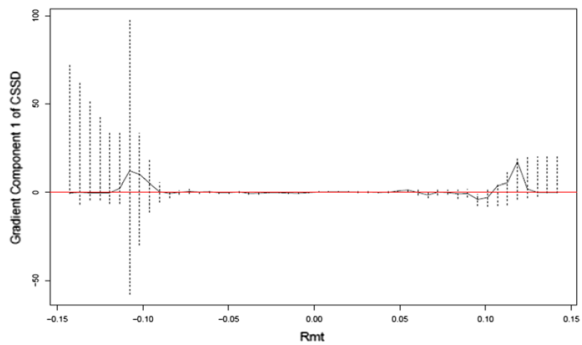

(b) Gradients

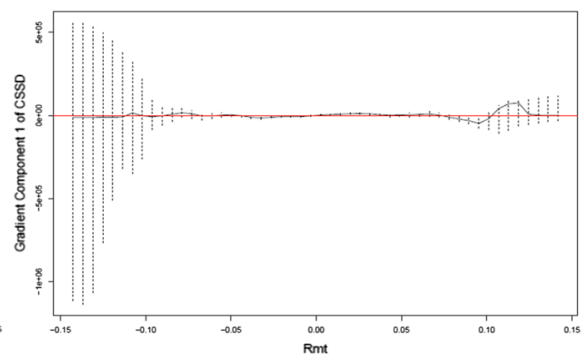

(b) Gradients

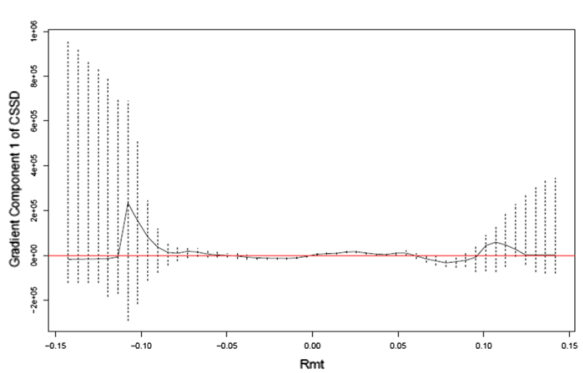

(b) Gradients

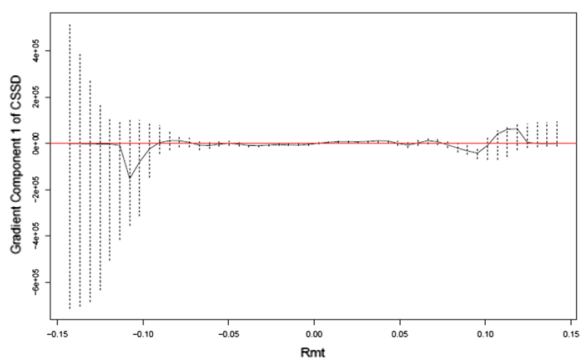

(b) Gradients 
CSAD

Consumer Discretionary

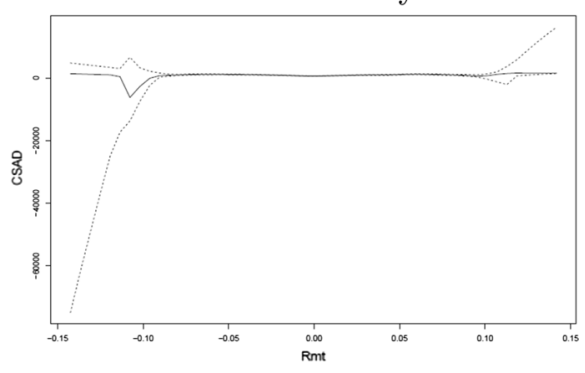

(a) $\mathrm{E}(\mathrm{Y} \mid \mathrm{X})$

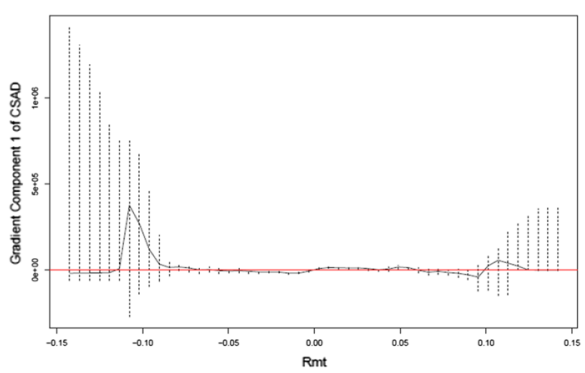

(b) Gradients

\section{Consumer Staples}

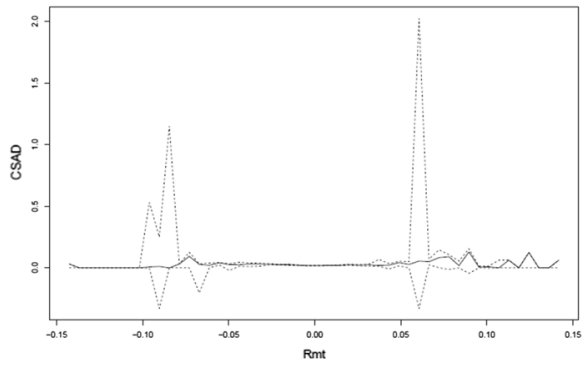

(a) $\mathrm{E}(\mathrm{Y} \mid \mathrm{X})$

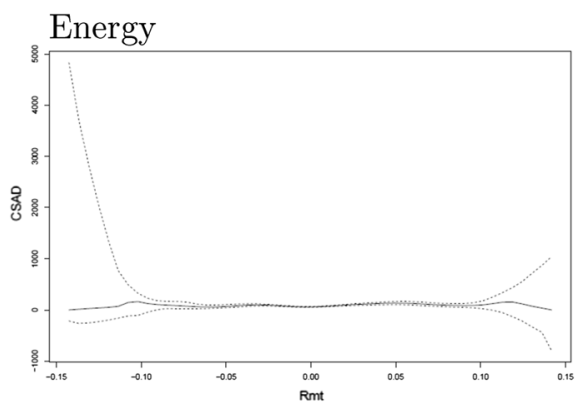

(a) $\mathrm{E}(\mathrm{Y} \mid \mathrm{X})$

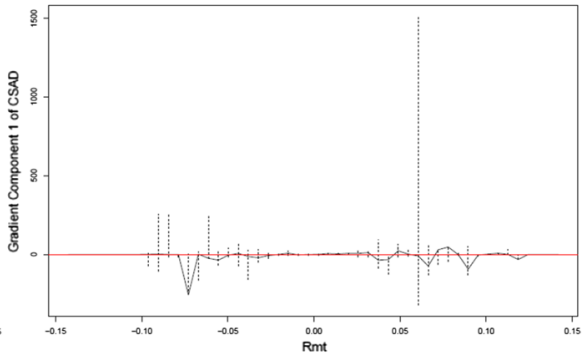

(b) Gradients

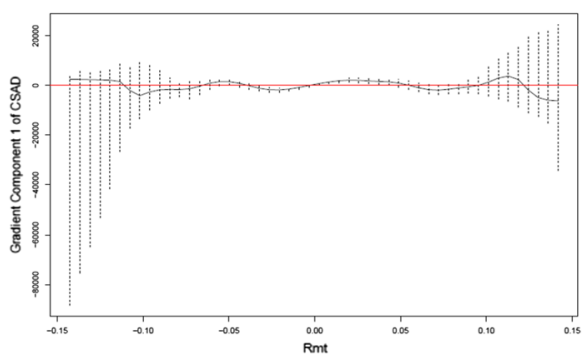

(b) Gradients 


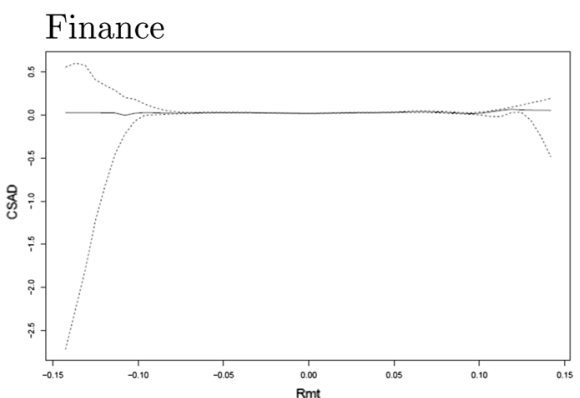

(a) $\mathrm{E}(\mathrm{Y} \mid \mathrm{X})$

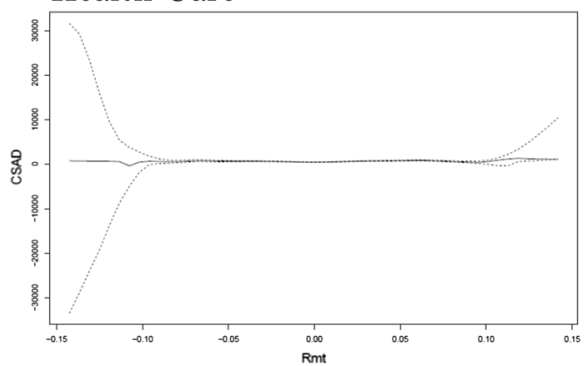

(a) $\mathrm{E}(\mathrm{Y} \mid \mathrm{X})$

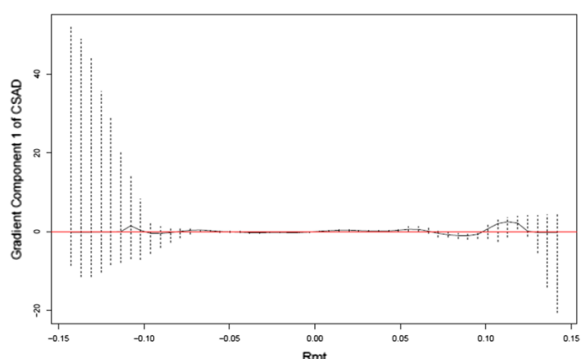

(b) Gradients

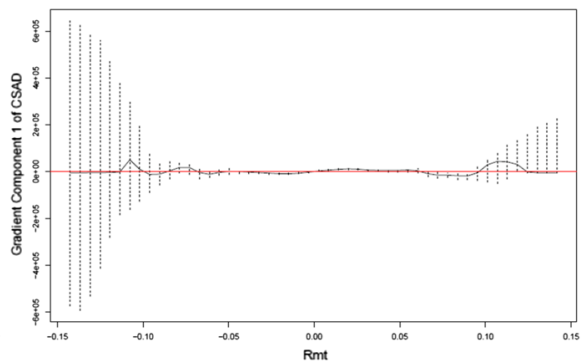

(b) Gradients

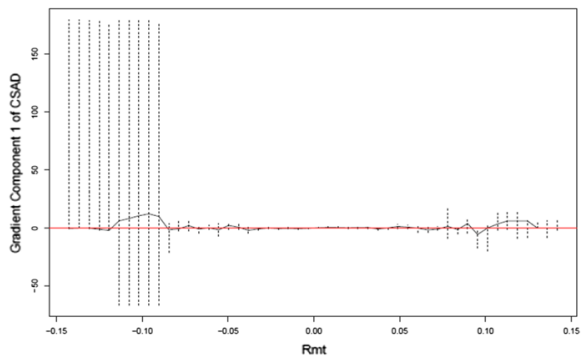

(b) Gradients

(a) $\mathrm{E}(\mathrm{Y} \mid \mathrm{X})$

Information Technology

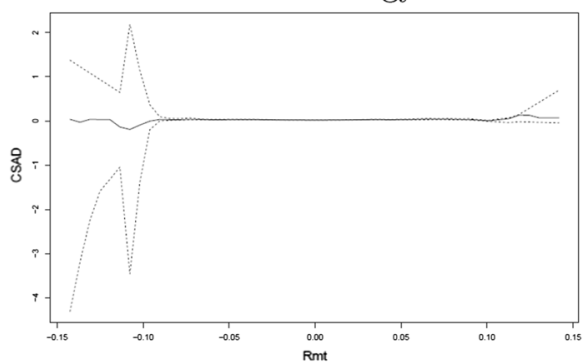

(a) $\mathrm{E}(\mathrm{Y} \mid \mathrm{X})$

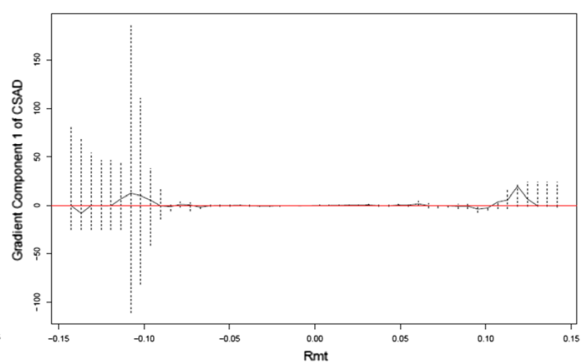

(b) Gradients 


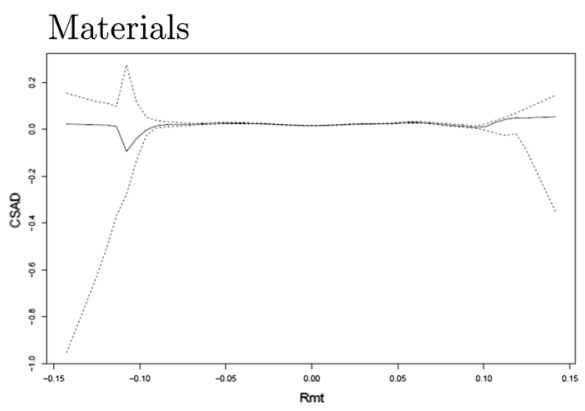

(a) $\mathrm{E}(\mathrm{Y} \mid \mathrm{X})$

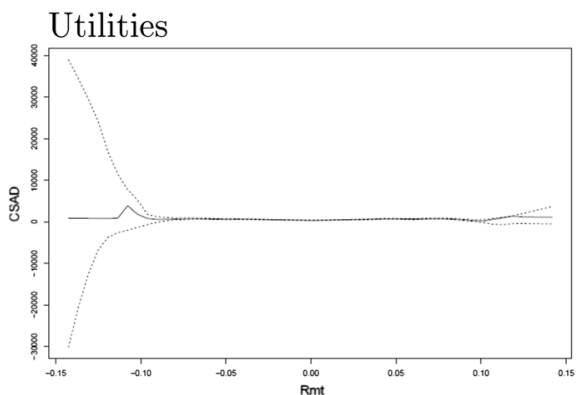

(a) $\mathrm{E}(\mathrm{Y} \mid \mathrm{X})$

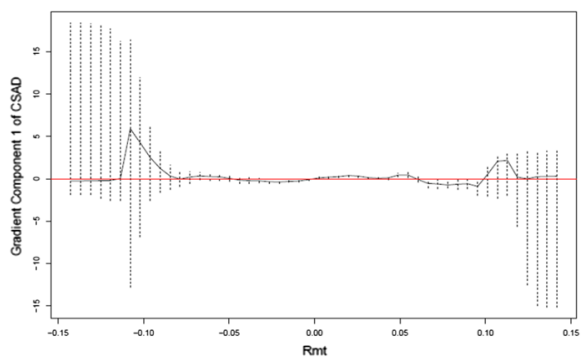

(b) Gradients

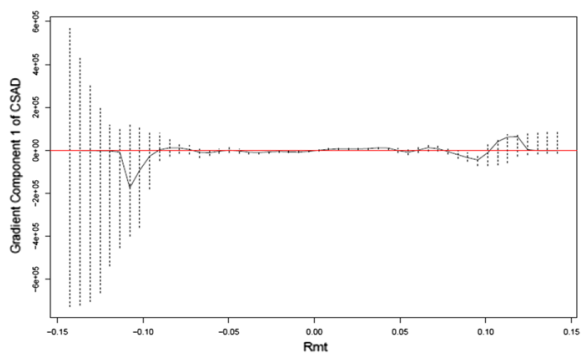

(b) Gradients

\section{References}

Belhoula M, Naoui K (2011) Herding and positive feedback trading in American stock market: a two co-directional behavior of/investors. Int J Bus Manag 6(9):244

Bikhchandani S, Hirshleifer D, Welch I (1992) A theory of fads, fashion, custom, and cultural change as informational cascades. J Political Econ 100(5):992-1026

Celik S (2013) Herd behavior in world stock markets: Evidence from quantile regression analysis. Iktisat Isletme ve Finans 28(329):75-96

Chan KC, Fung H-G, Thapa S (2007) China financial research: a review and synthesis. Int Rev Econ Finance 16(3):416-428

Chang EC, Cheng JW, Khorana A (2000) An examination of herd behavior in equity markets: an international perspective. J Bank Finance 24(10):1651-1679

Chiang TC, Li J, Tan L (2010) Empirical investigation of herding behavior in Chinese stock markets: evidence from quantile regression analysis. Global Finance J 21(1):111-124

Chiang TC, Li J, Tan L (2012) Does herding behavior in Chinese markets react to global markets? Int Rev Account Bank Finance 4(1)

Chiang TC, Li J, Tan L, Nelling E (2013) Dynamic herding behavior in Pacific-Basin markets: evidence and implications. Multinatl Finance J 17(3/4):165-200

Christie WG, Huang RD (1995) Following the pied piper: do individual returns herd around the market? Finance Anal J 51(4):31-37

Clement MB, Tse SY (2005) Financial analyst characteristics and herding behavior in forecasting. J Finance 60(1):307-341

Demirer R, Kutan AM (2006) Does herding behavior exist in Chinese stock markets? J Int Finance Mark Inst Money 16(2):123-142

Devenow A, Welch I (1996) Rational herding in financial economics. Eur Econ Rev 40(3):603-615

Fan J, Gijbels I (1996) Local polynomial modelling and its applications: monographs on statistics and applied probability, vol 66. CRC Press, Boca Raton

Fu T (2010) Herding in China equity market. Int J Econ Finance 2(2):148 
Gibbons JD, Chakraborti S (2011) Nonparametric statistical inference. Springer, Berlin

Gleason CA, Lee CMC (2003) Analyst forecast revisions and market price discovery. Account Rev 78:193225

Hayfield T, Racine JS (2008) Nonparametric econometrics: the np package. J Stat Softw 27(5):1-32

Hsiao C, Li Q, Racine JS (2007) A consistent model specification test with mixed discrete and continuous data. J Econom 140(2):802-826

Hurvich CM, Simonoff JS, Tsai C-L (1998) Smoothing parameter selection in nonparametric regression using an improved Akaike information criterion. J R Stat Soc Ser B Stat Methodol 60(2):271-293

Hwang S, Salmon M (2004) Market stress and herding. J Empir Finance 11(4):585-616

Kendall MG (1948) Rank correlation methods

Liu RY et al (1988) Bootstrap procedures under some non-iid models. Ann Stat 16(4):1696-1708

Pagan A, Ullah A (1999) Nonparametric econometrics. Cambridge University Press, Cambridge

Scharfstein DS, Stein JC (1990) Herd behavior and investment. Am Econ Rev 80(3):465-479

Su L, Ullah A (2006) Profile likelihood estimation of partially linear panel data models with fixed effects. Econ Lett 92(1):75-81

Su L, Ullah A, Wang Y (2013) Nonparametric regression estimation with general parametric error covariance: a more efficient two-step estimator. Empir Econ 45(2):1009-1024

Tan L, Chiang TC, Mason JR, Nelling E (2008) Herding behavior in Chinese stock markets: an examination of A and B shares. Pac-Basin Finance J 16(1):61-77

Wermers R (1999) Mutual fund herding and the impact on stock prices. J Finance 54(2):581-622

Yao J, Ma C, He WP (2014) Investor herding behaviour of Chinese stock market. Int Rev Econ Finance 29:12-29

Yu K, Jones MC (1997) A comparison of local constant and local linear regression quantile estimators. Comput Stat Data Anal 25(2):159-166

Zhou H (2007) Herding in dual-share stock markets: evidence from China. J Emerg Mark 12(2):5 